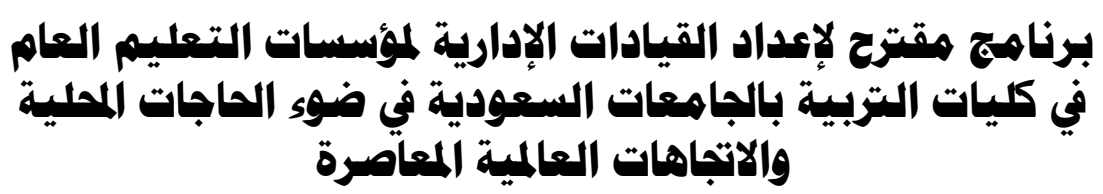

د/ عائشتَ بنت بكر آدم فلاته

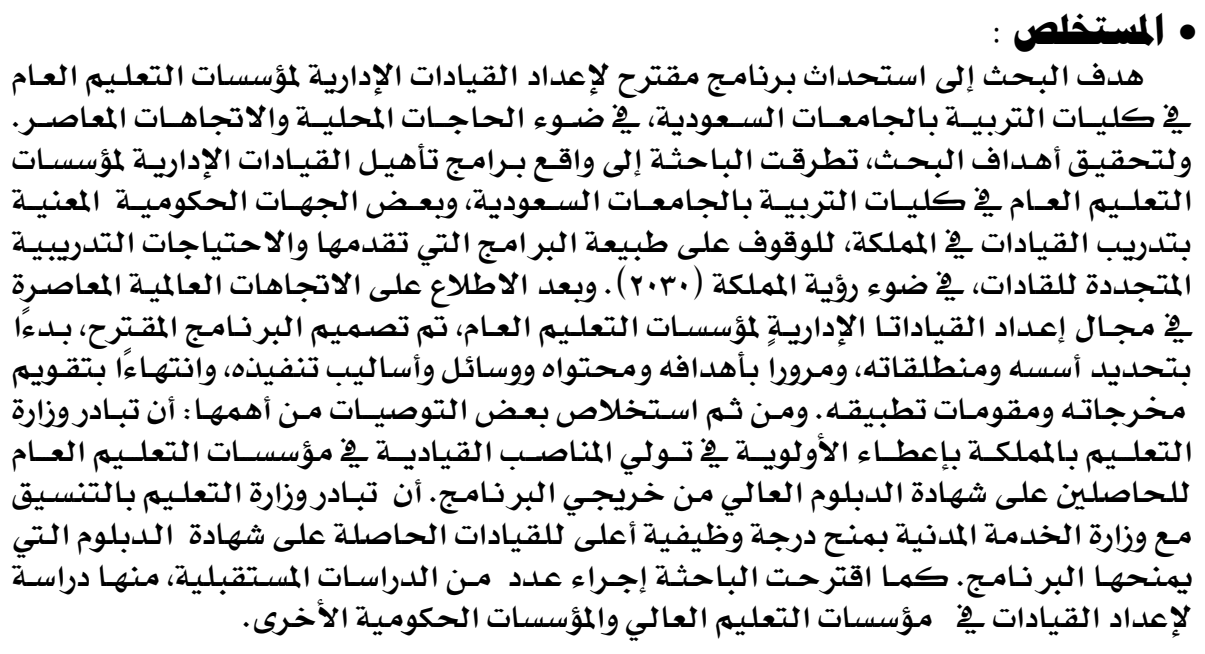

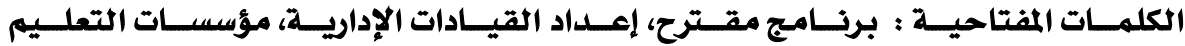

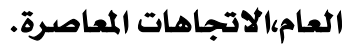

A Proposed Program For Preparing Administrative Leaders of

Public Schools at College of Education in Saudi Universities According to the Leaders Need and Current Global Trends

\title{
Dr.Aisha Fallatah
}

\section{Abstract:}

The study aimed to propose a program for preparing administrative leaders of puplic schools in Saudi Arabia at educational faculties in Saudi universities. To achieve the study objectives, the researcher investigated the national needs as well as the international trends regarding the process of preparing educational administrative leaders for puplic schools. The researcher discussed the foundation and premises of education in Saudi Arabia in relation to the vision (2030) of the Saudi Arabian kingdom, in order to propose a program including its objectives, contents, means, and implementation, and to evaluate its outcomes. At last, the researcher stated some recommendations and suggestions for future studies.

Keywords: Preparation Programs, Schools Leaders, Faculties of Education.

\section{Yr}




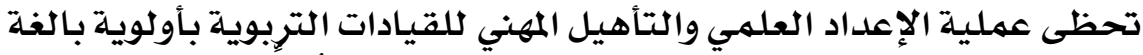

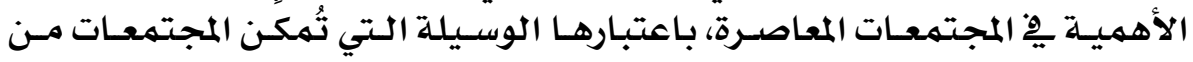

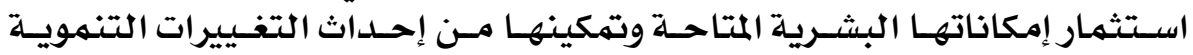

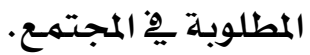

وتعتبر عملية إعداد وتأهيل القيادات الإدارية لمؤسسات التعليم العـام مـن أهـم

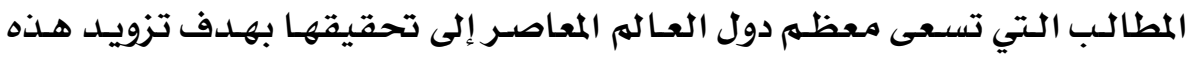

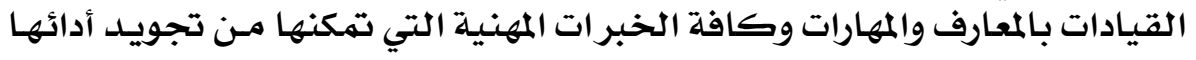

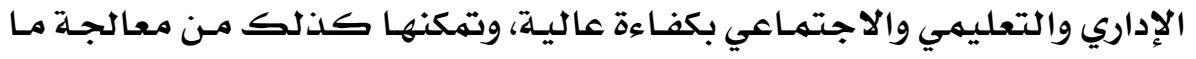

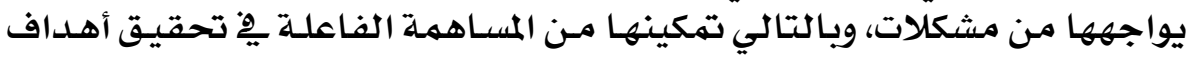
المؤسسات التربوية التي تتولى قيادتها.

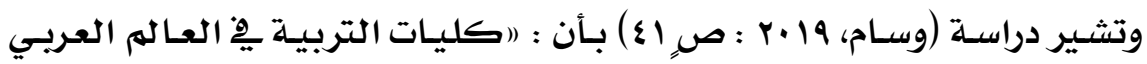

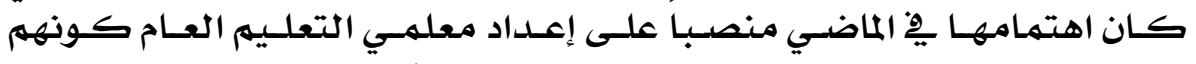

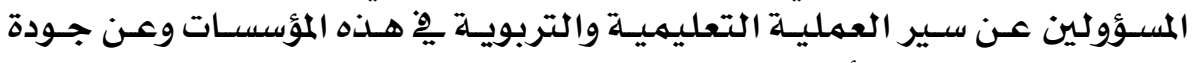

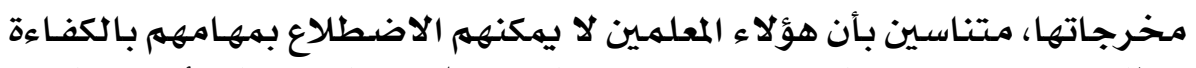

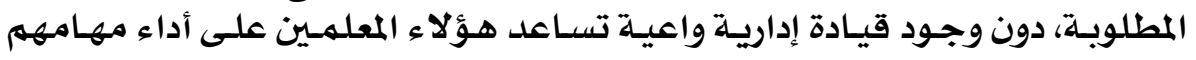

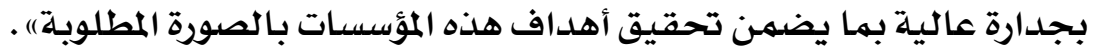

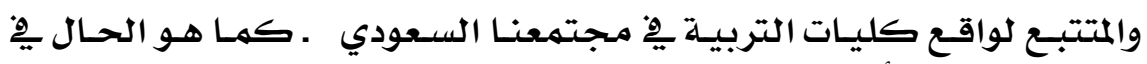

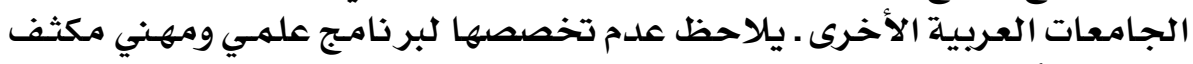

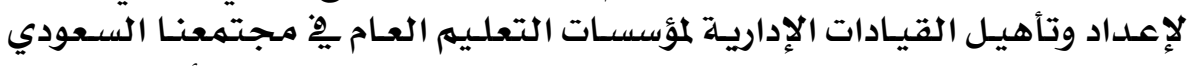

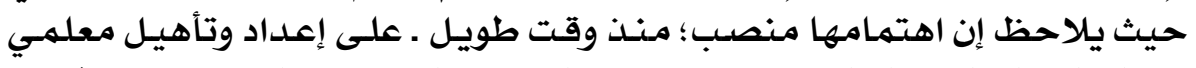

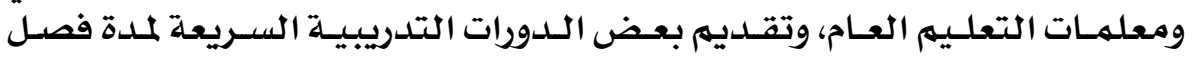

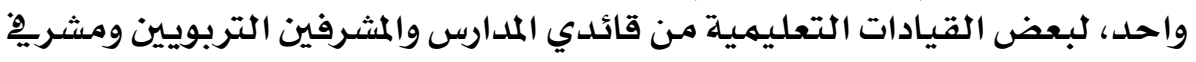

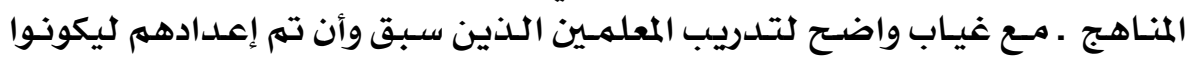
قيادات مستقبلية.

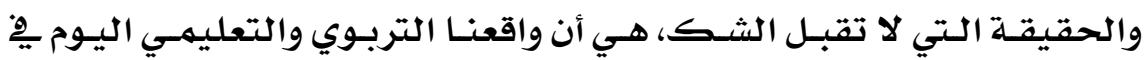

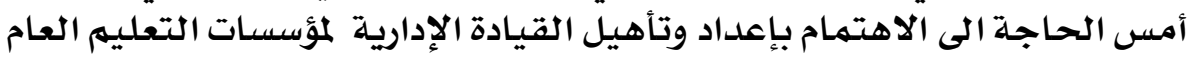

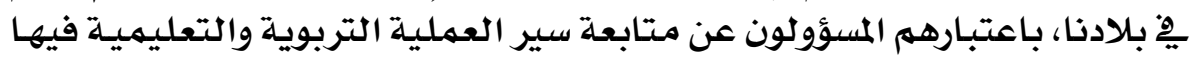

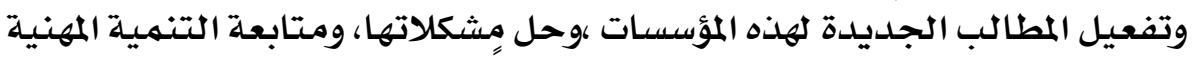

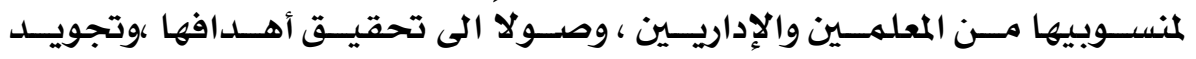

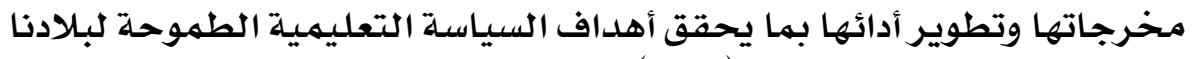

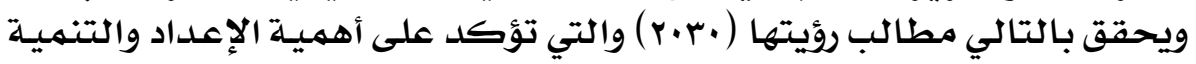
المهنية المستدامة للقيادات التربوية يِّ البلاد.

\section{r₹}




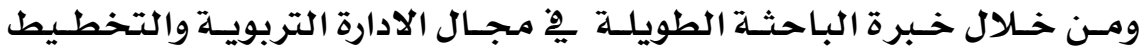

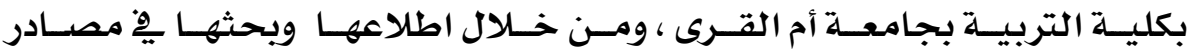

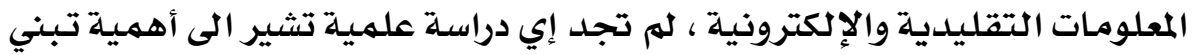

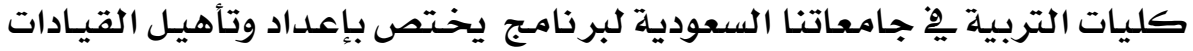

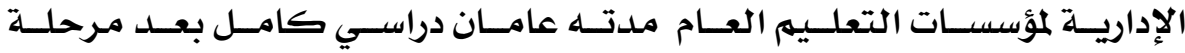

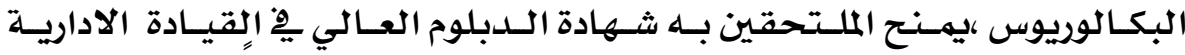

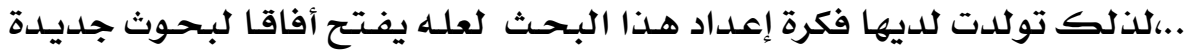

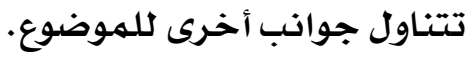

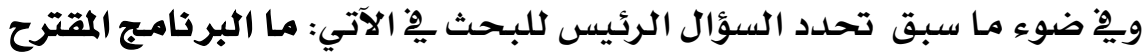

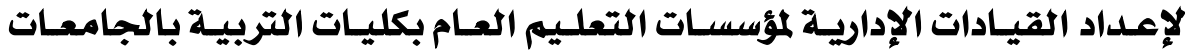

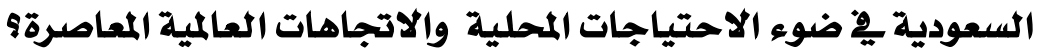
ويتفرع من السؤال الرئيس الأسئلة الفرعية التالية:

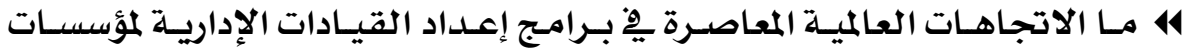
التعليهم العام ؟ ماتجات

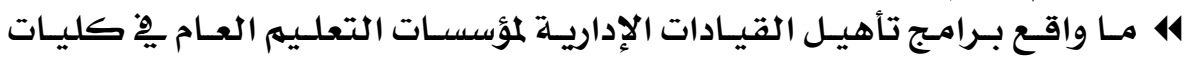

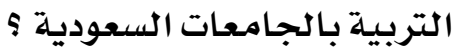

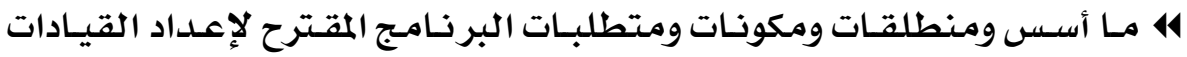

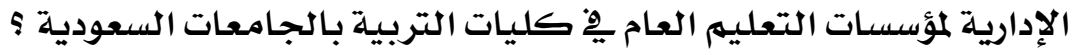

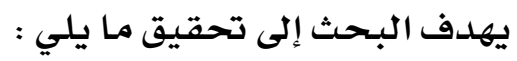

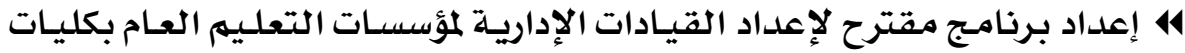

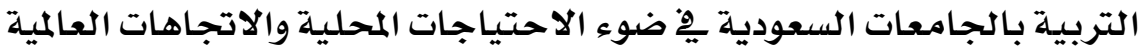
المعاصرة.

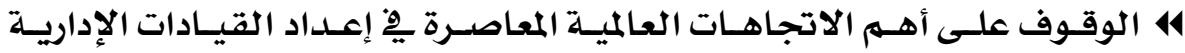

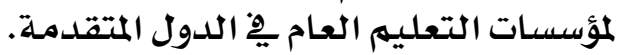

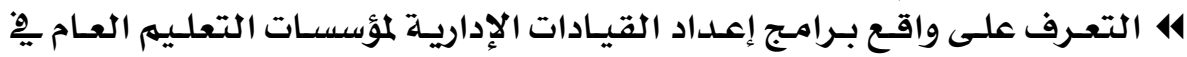

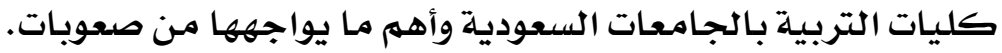

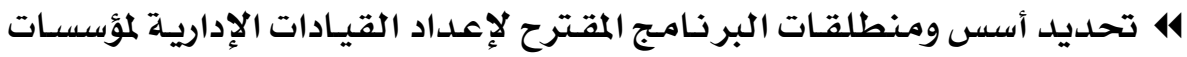

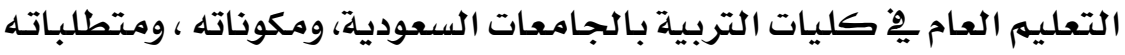

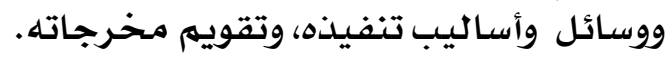

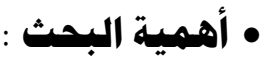

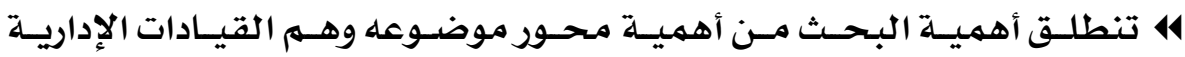

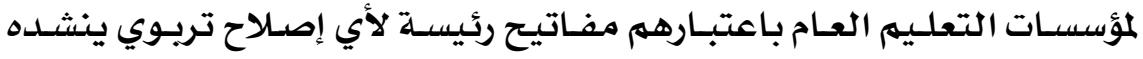
المجتهـع المؤستات

\section{Yo}




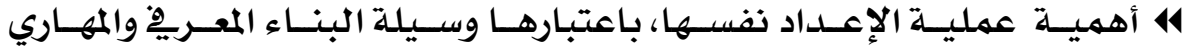

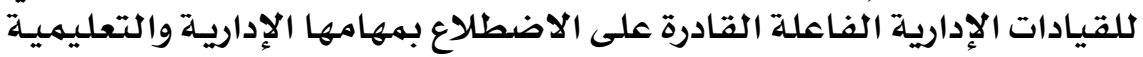

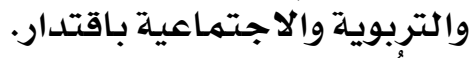

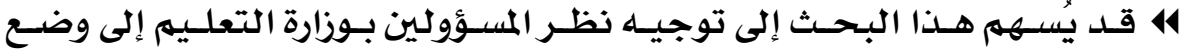

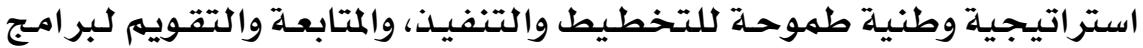

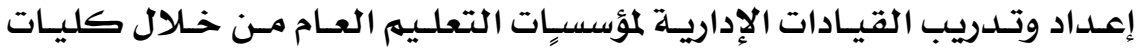

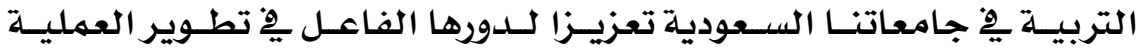

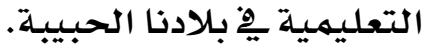

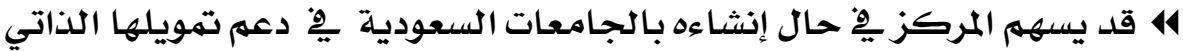

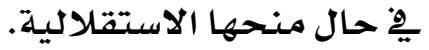

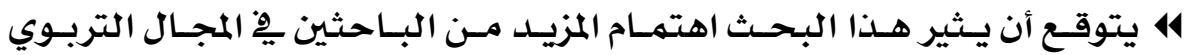

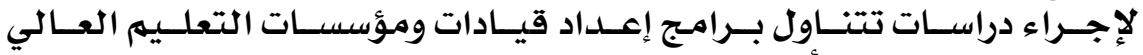

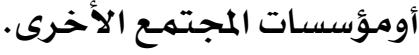

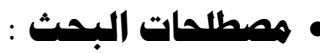

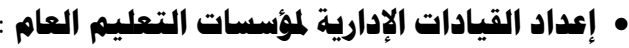

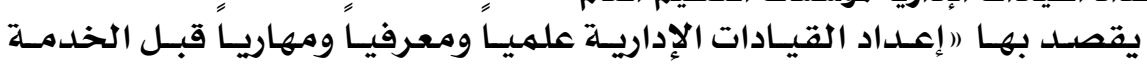

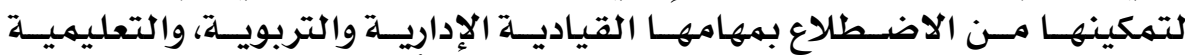

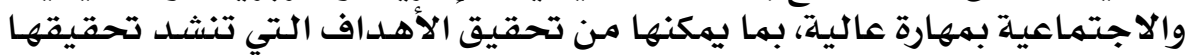

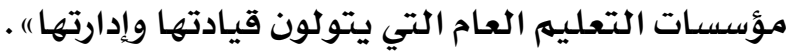

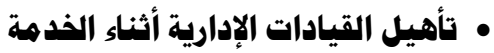

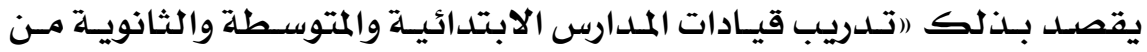

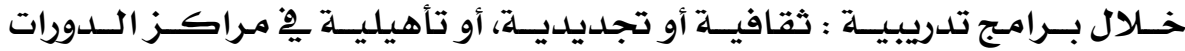

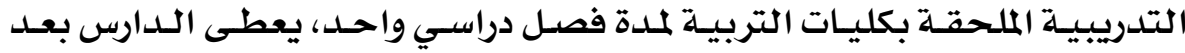

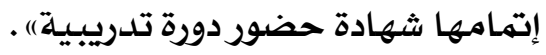

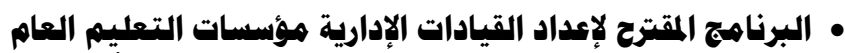

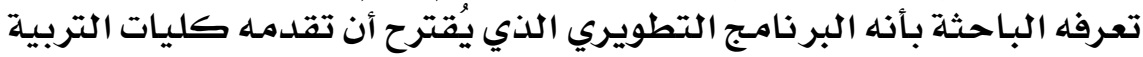

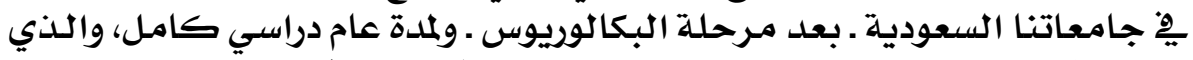

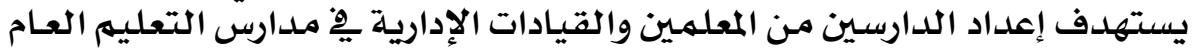

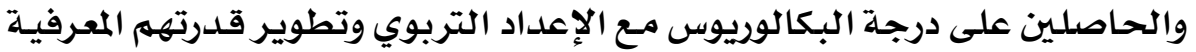

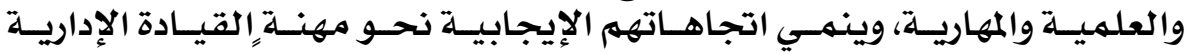

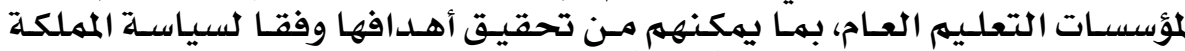

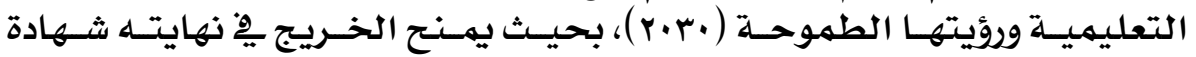

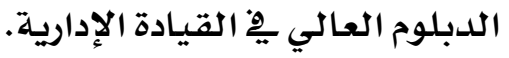

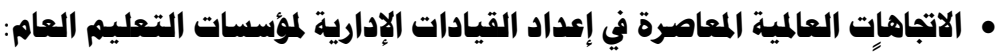

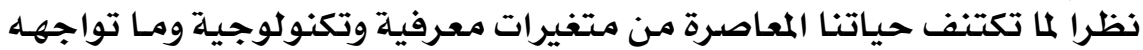

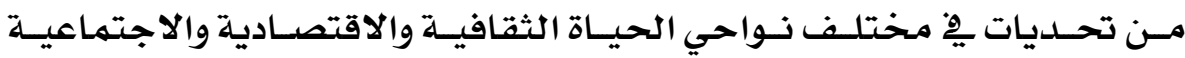

\section{Y 7}




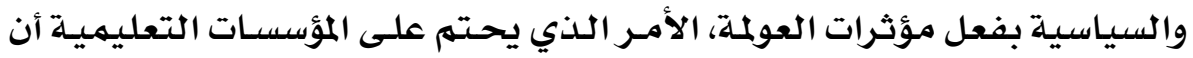

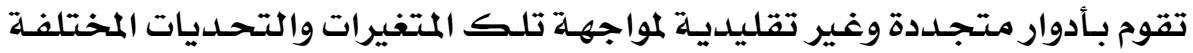

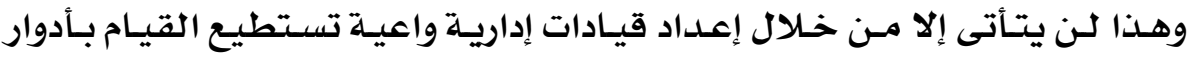

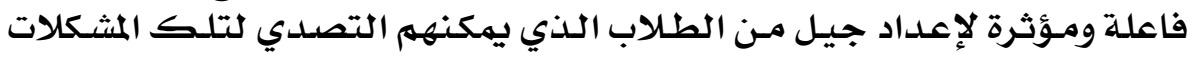

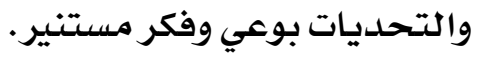

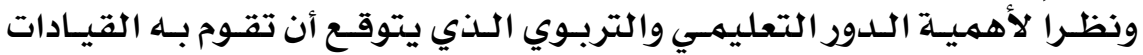

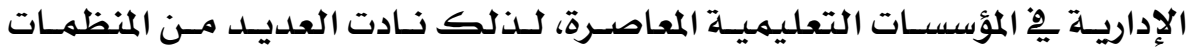

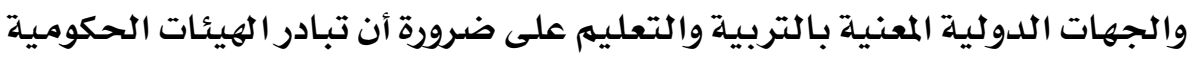

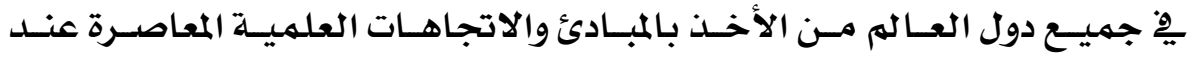

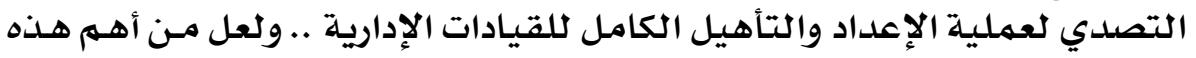
المطالب :

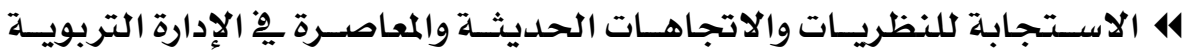

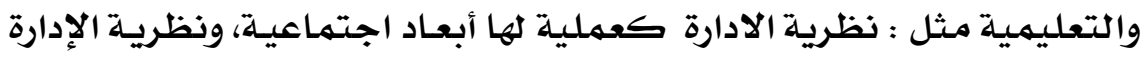

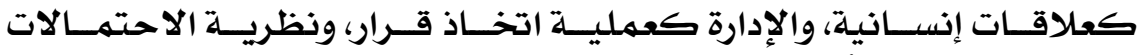

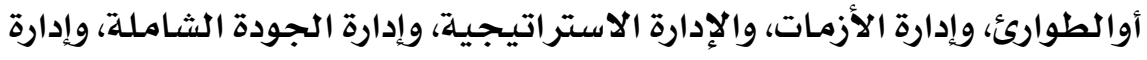
المعرفة، وإدارة التغيير، والهارة الإدارة والإدارة الالكترونية.

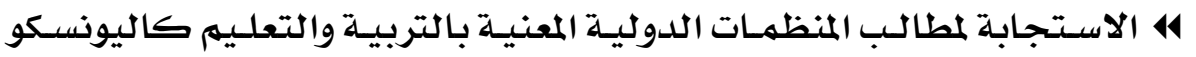

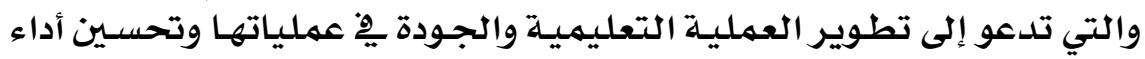

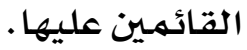

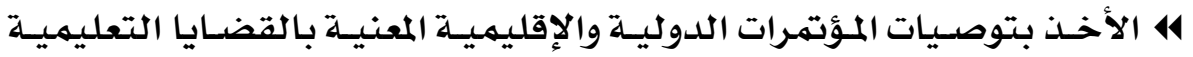

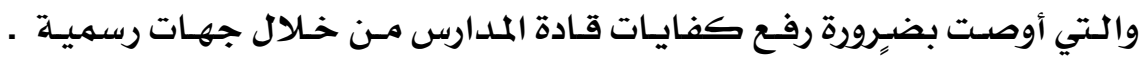

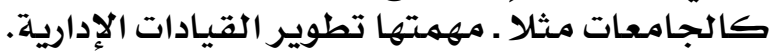

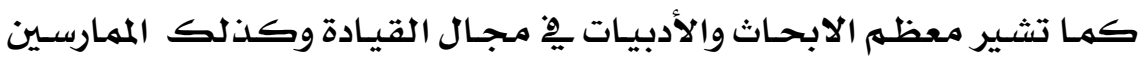

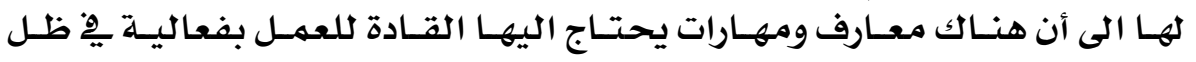

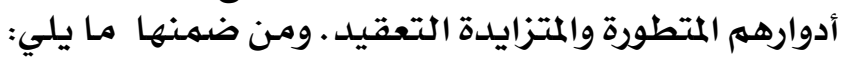

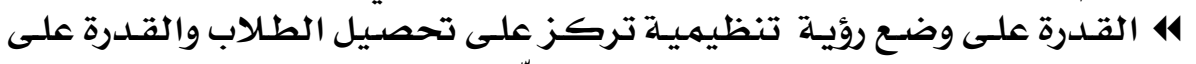

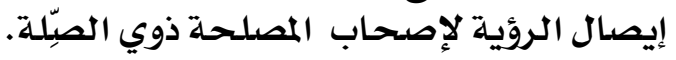

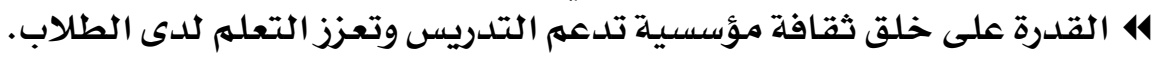

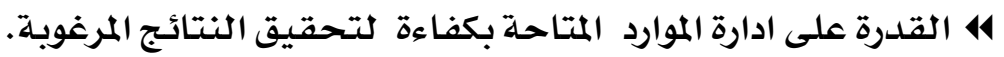

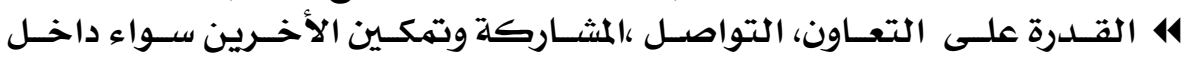

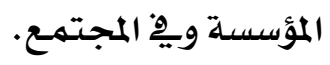

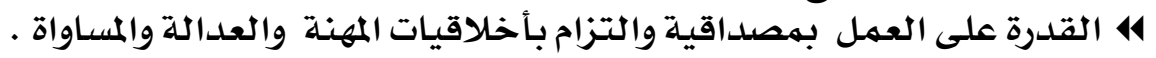

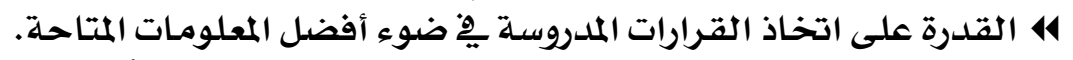
4 القدرة على التطور والنمو الذاتي ودعمم وتطوير مهمارسات الأخرين.

\section{YV}




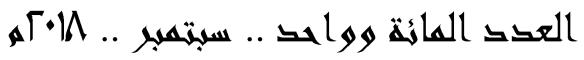

• واقع براهج تأهيل القيادات الإدارية لمؤسسات التعليم العام في كليات التربية بجاهعاتنا السعودية وبعض الجهات الهكوهية:

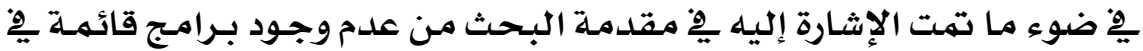

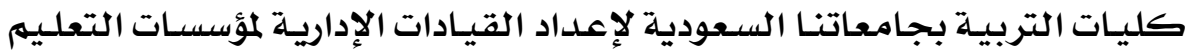

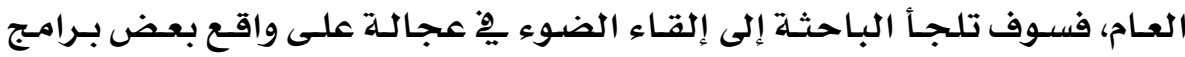

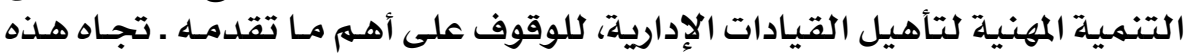

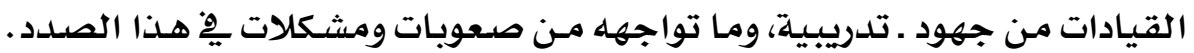

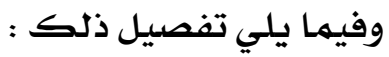

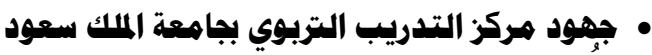

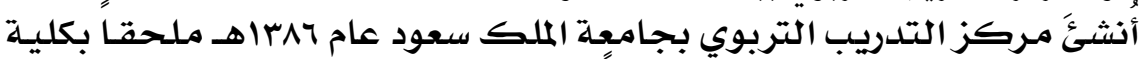

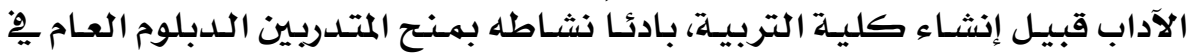

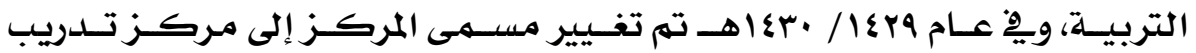

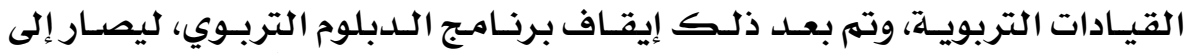

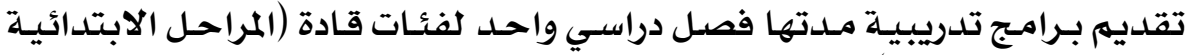

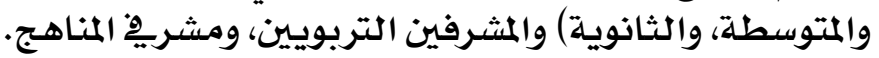

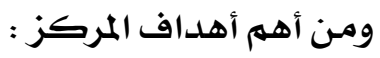

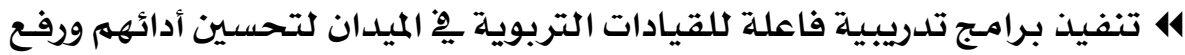

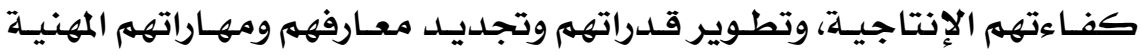

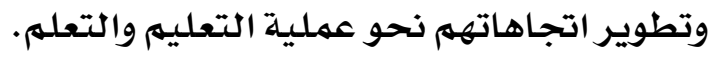

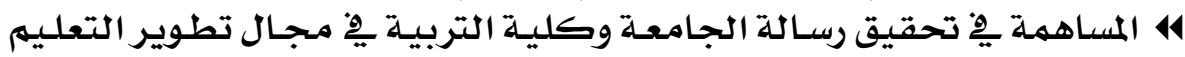
والتدريب.

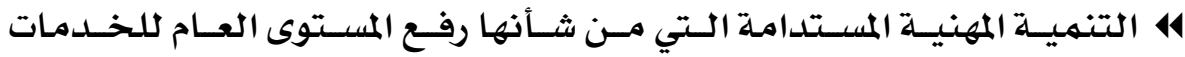

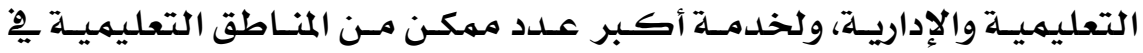
المملكة.

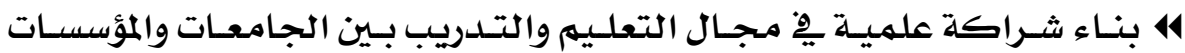

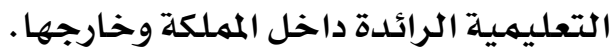

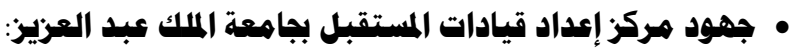

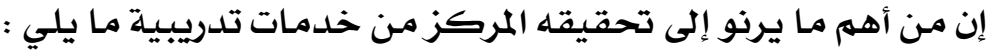

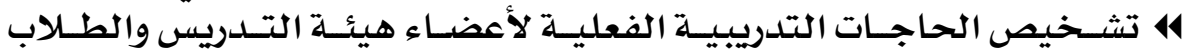

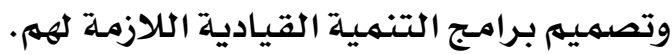

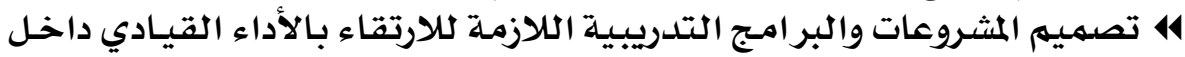

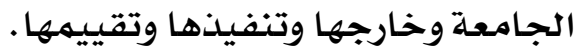

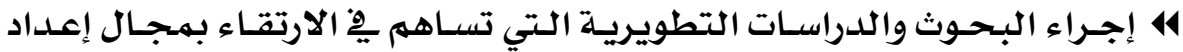
القيادات الناجحة واتوات والمبدعة.

\section{YA}




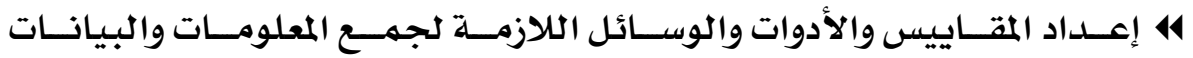

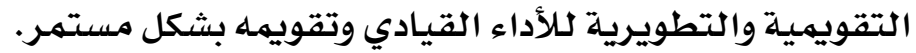

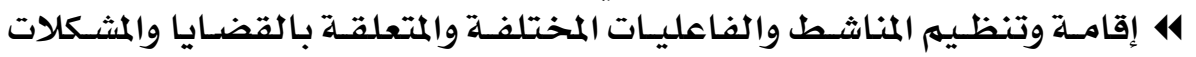
العصريـة يْ مجال القيادة الإدارية.

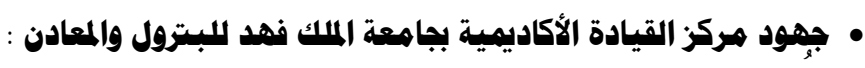

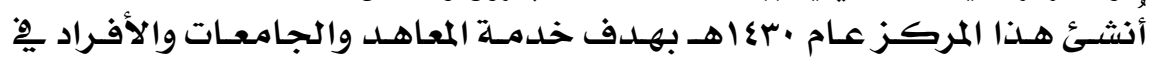

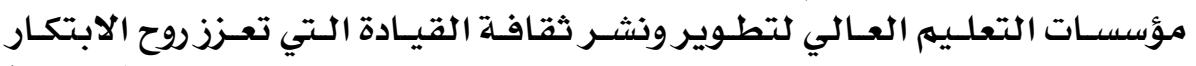

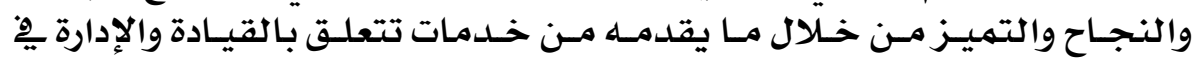
مجال التعليه العالي.

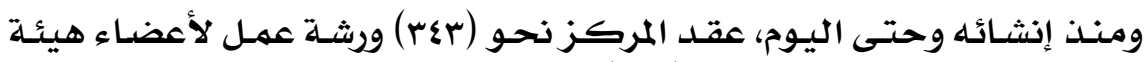

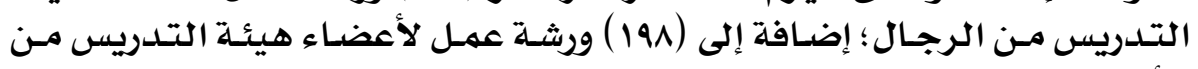
الأقسسام النسـائية.

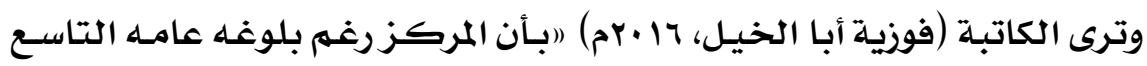

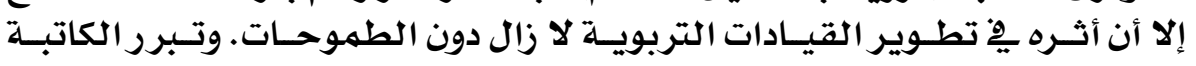

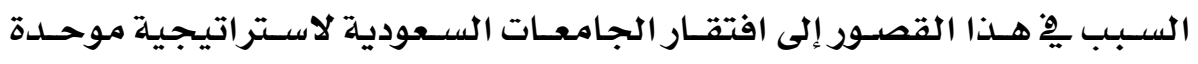

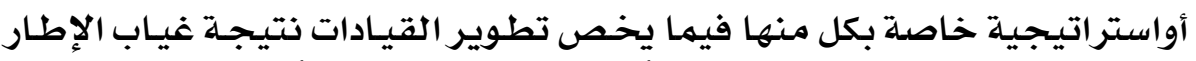

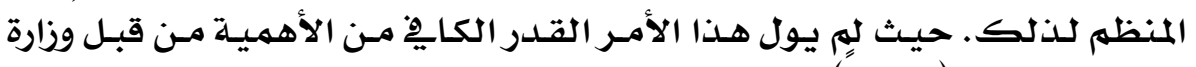

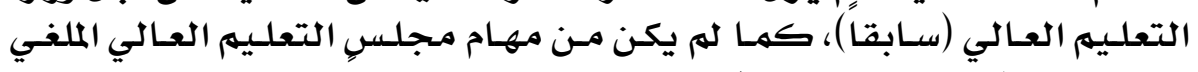

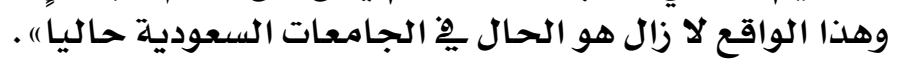

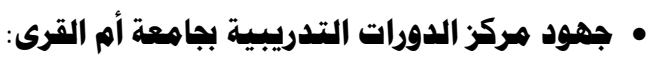

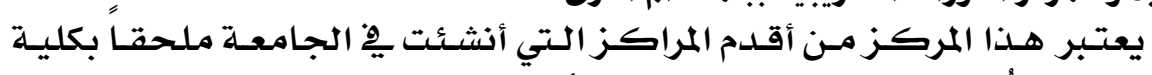

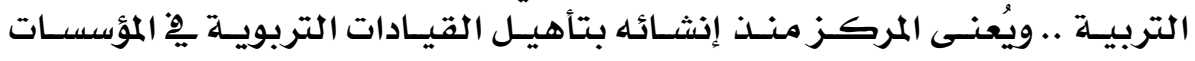

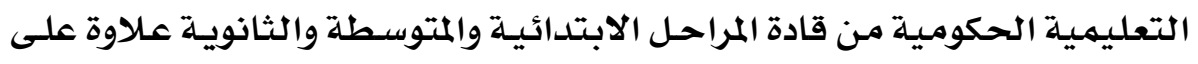

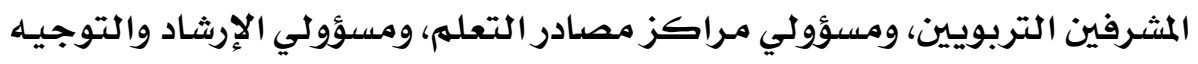

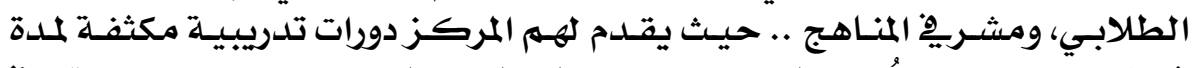

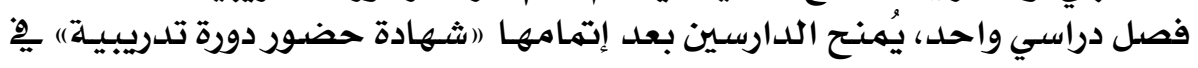

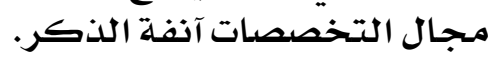

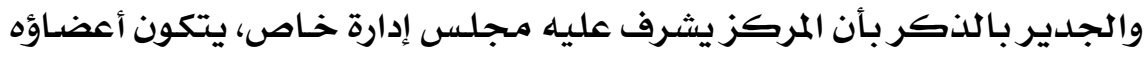

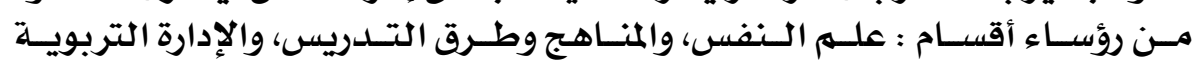

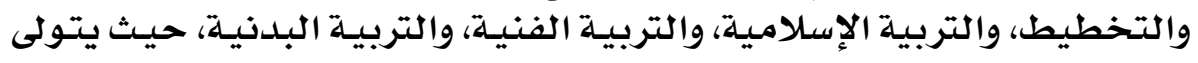

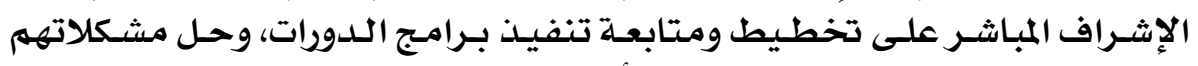

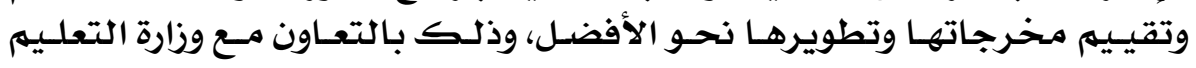

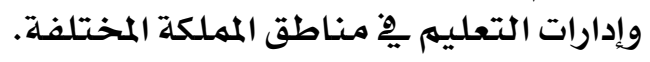

\section{Yq}




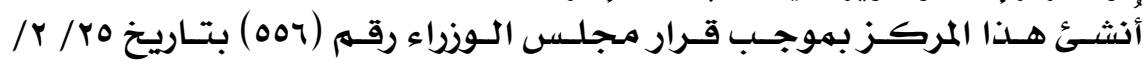

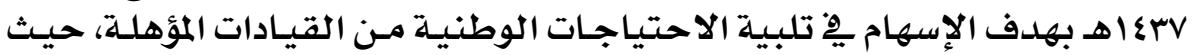

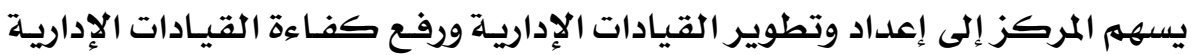

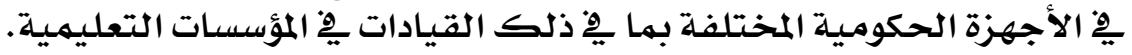

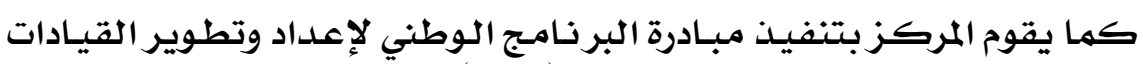

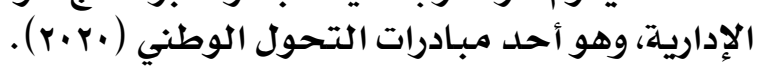

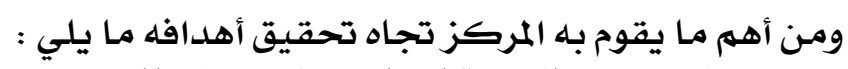

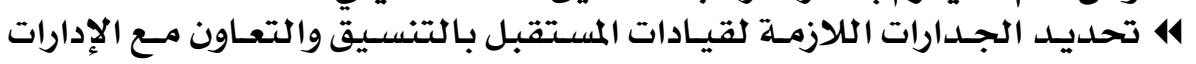

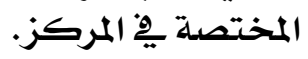

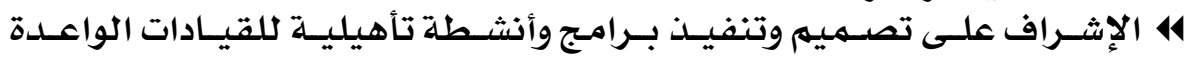

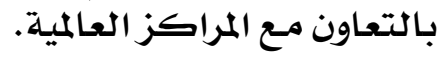

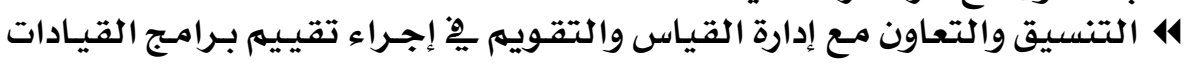

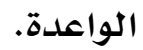

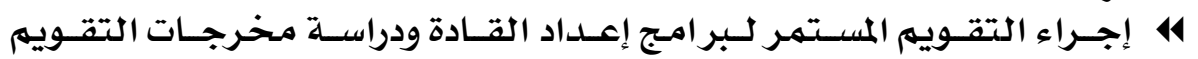
وتطويرها.

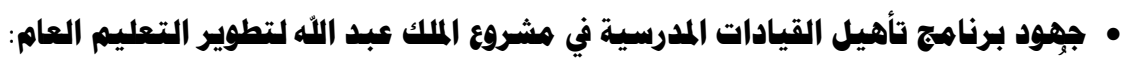

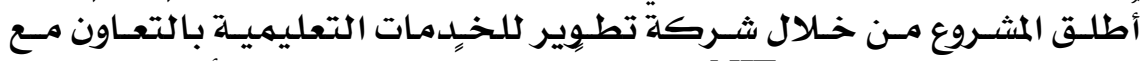

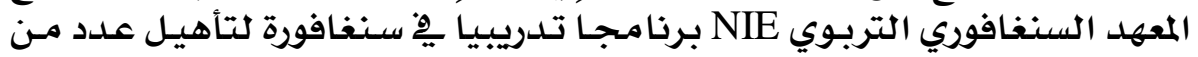

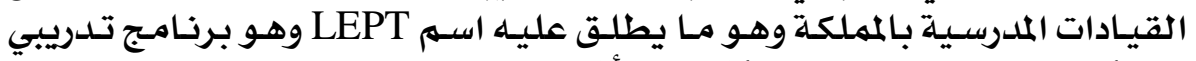

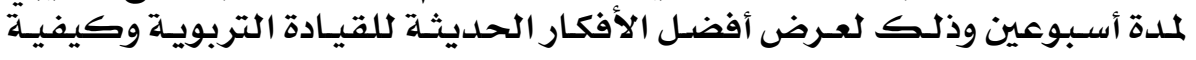
تحقيقها للنجاح.

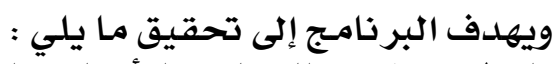

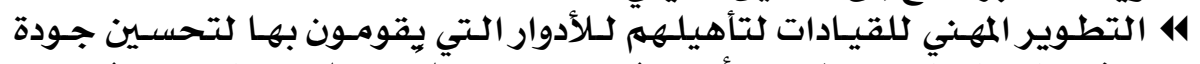

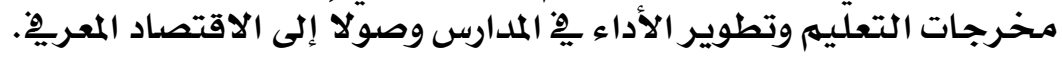

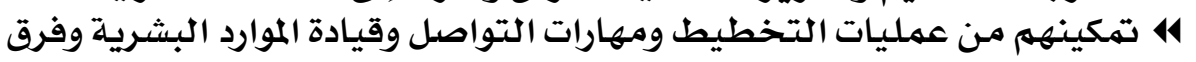
العهل.

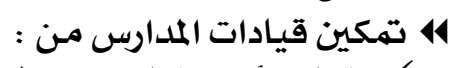

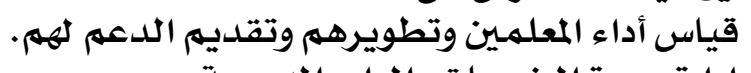

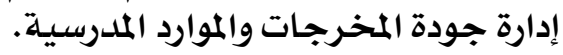

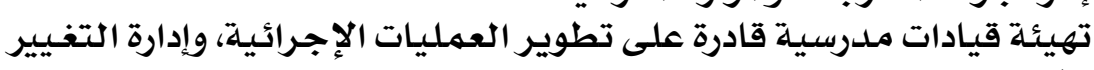

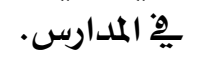

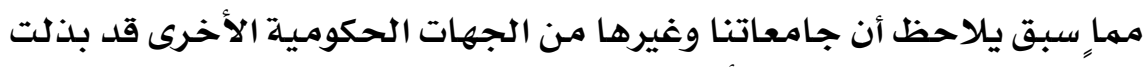

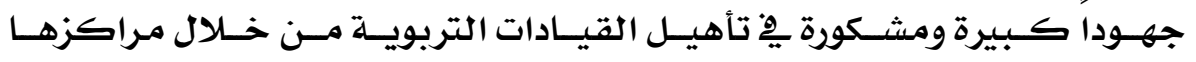

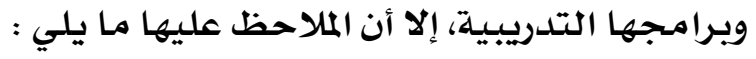

\section{$\mu$.}




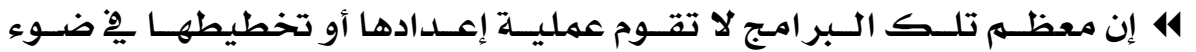

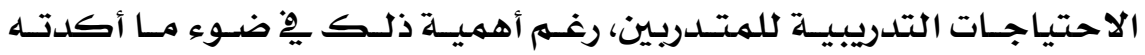

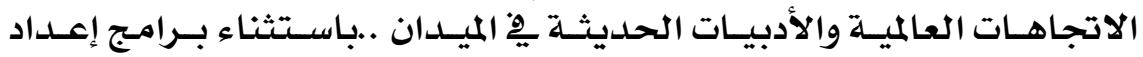

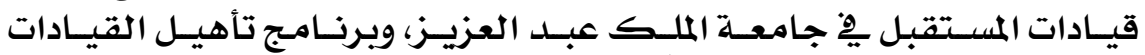

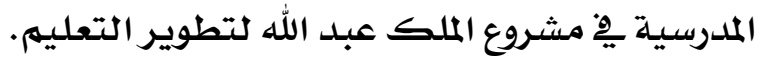

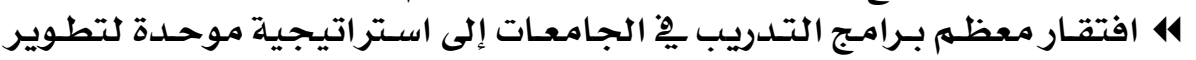

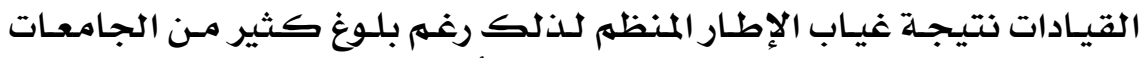

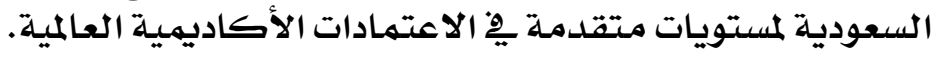

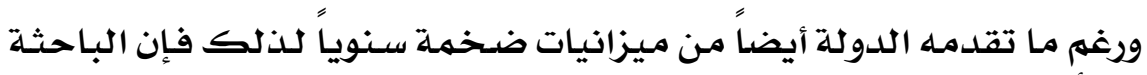

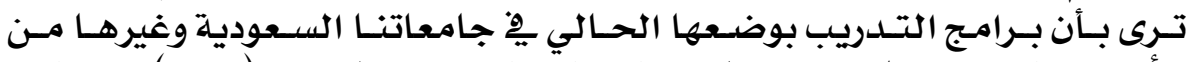

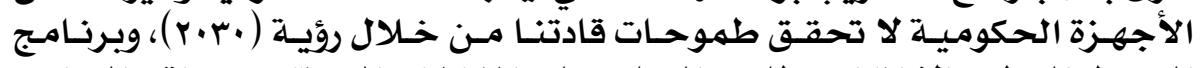

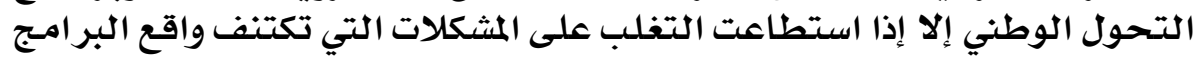

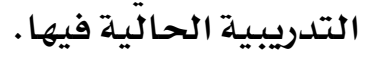

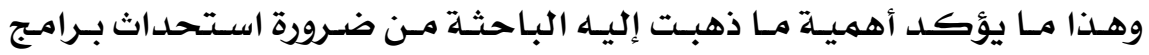

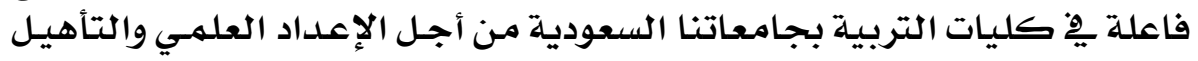

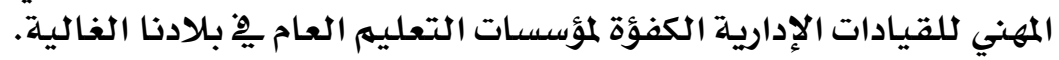

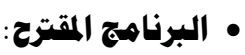

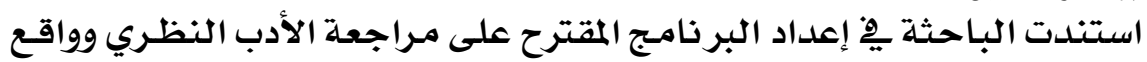

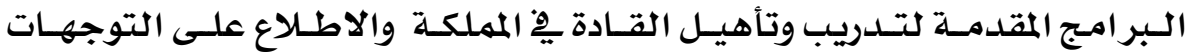

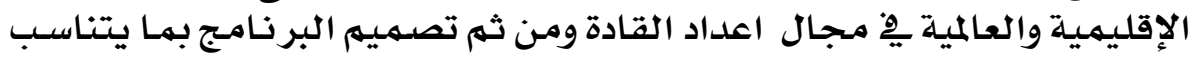

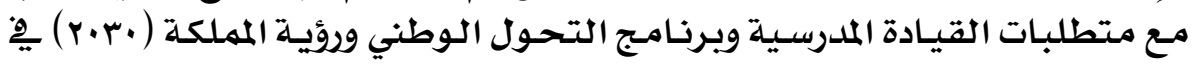

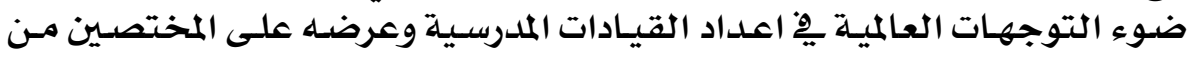

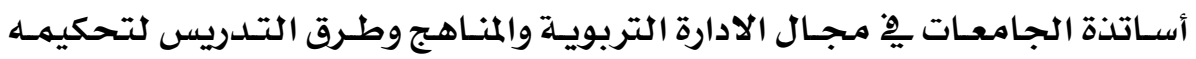

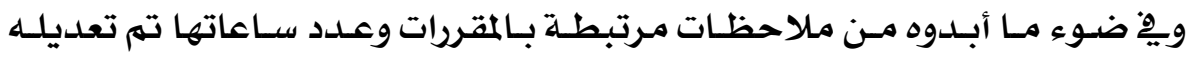

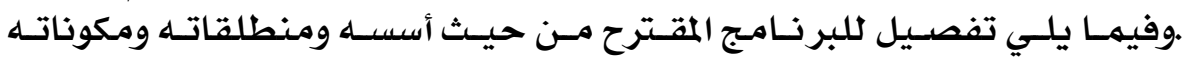

ووسائل وأساليب تنفيذه تفيل وتقويمـه.

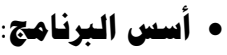

وتشمل:

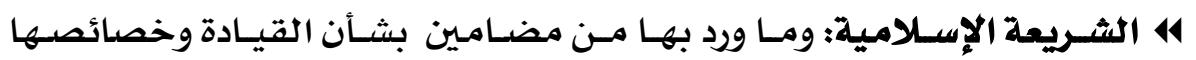

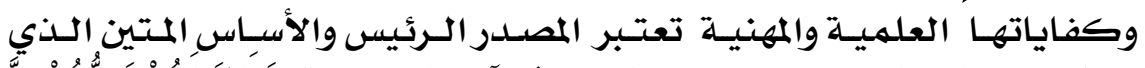

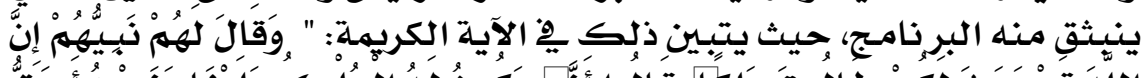

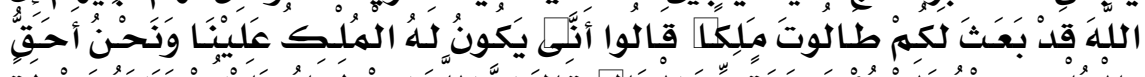

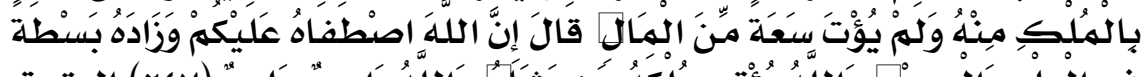

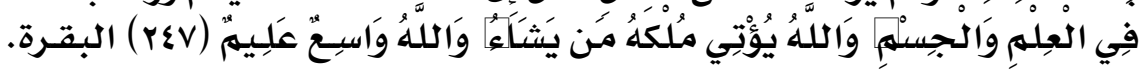

\section{Y}




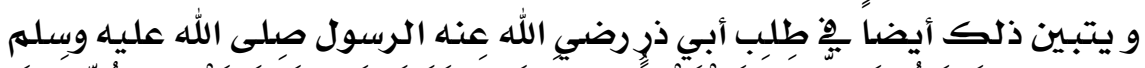

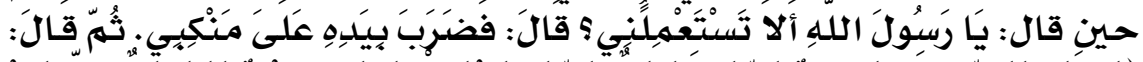

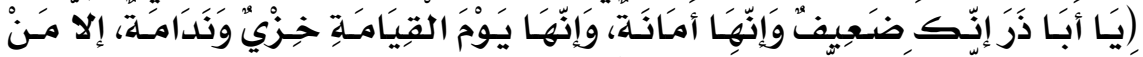

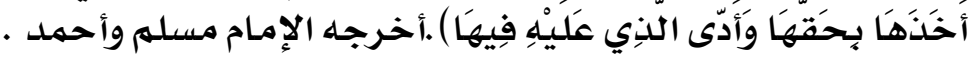

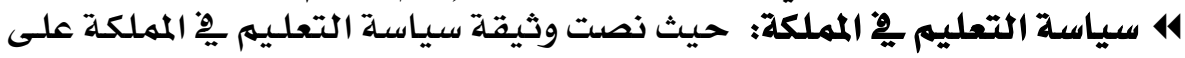

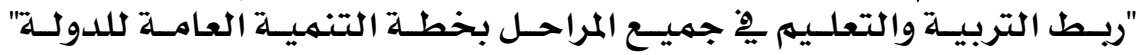

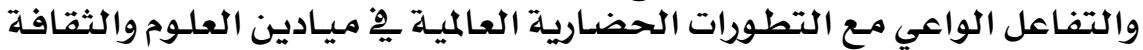

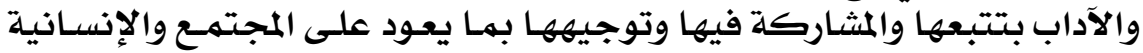

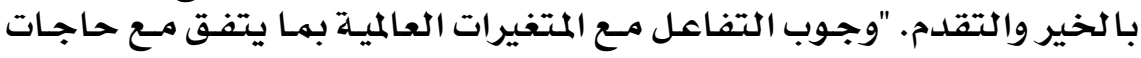
المجتهـع ويحافظ على هويته"

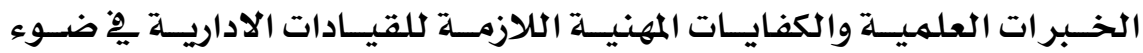

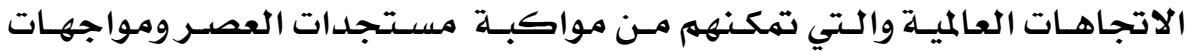

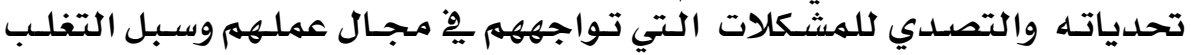

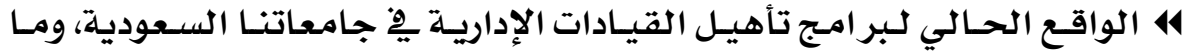

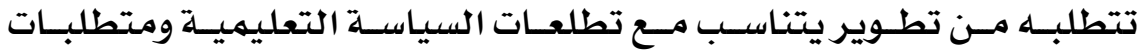
التتمية الشـاملة يِّ البـلاد.

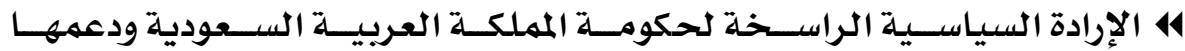

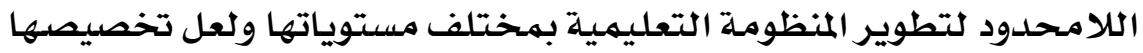

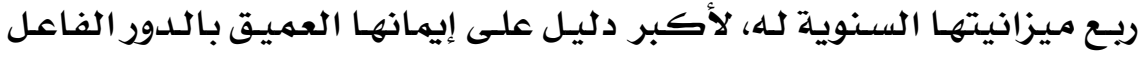

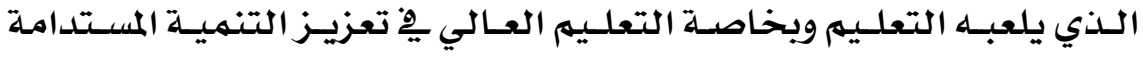

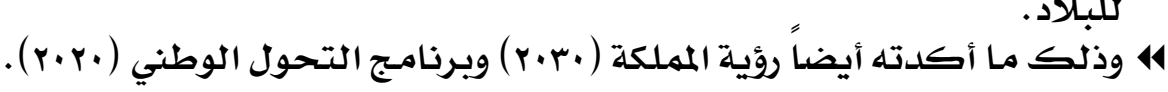

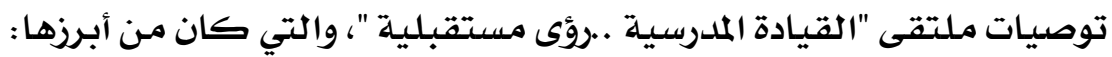

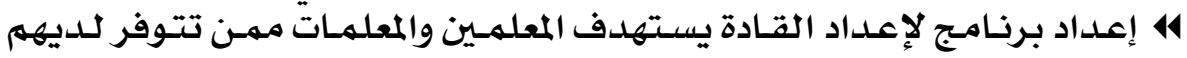
السهمات القيادية.

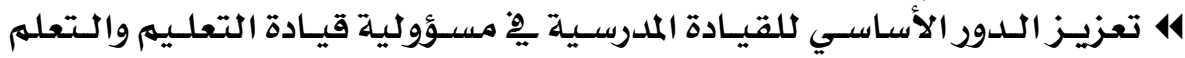

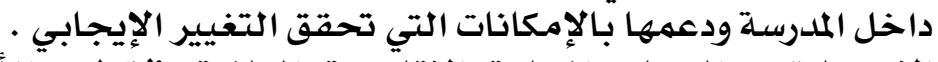

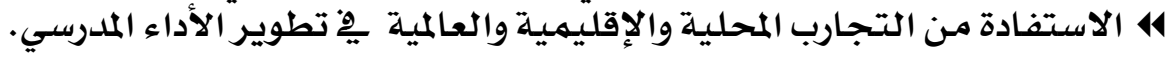

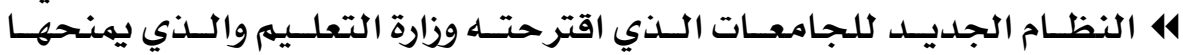

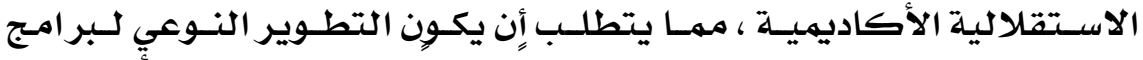

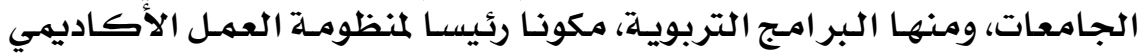
والتدريبي يِّ جامعاتنا السعودية.

\section{MY}




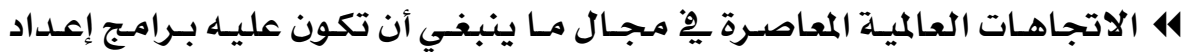

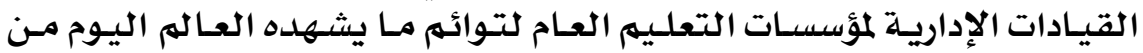

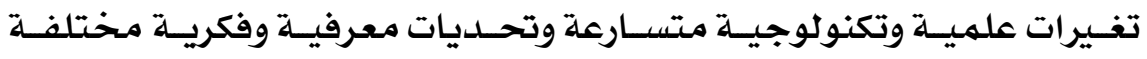

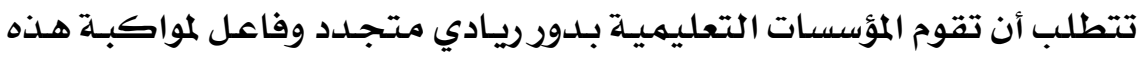

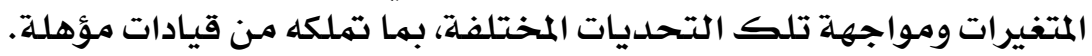

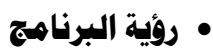

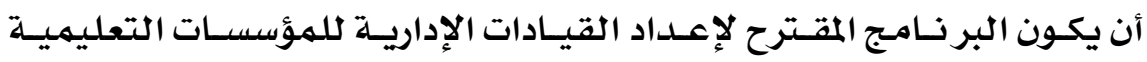

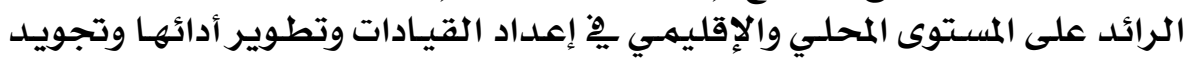

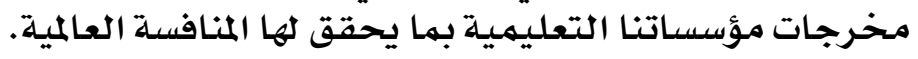

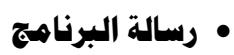

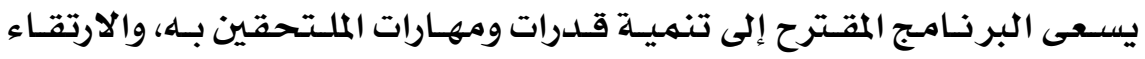

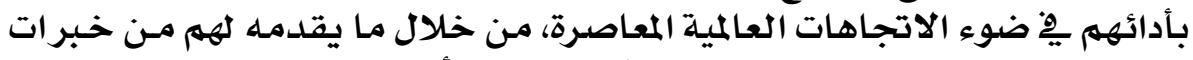

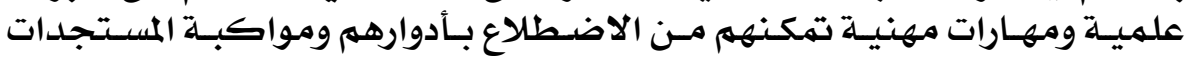

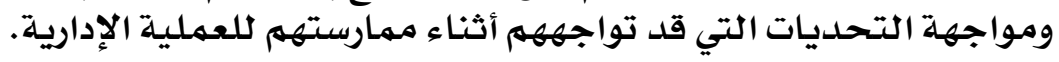

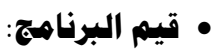

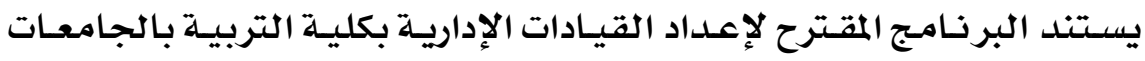

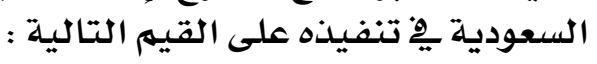

414 14 - 24 الإتقان. 14 المسؤولية. 414 414

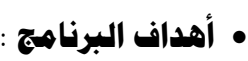

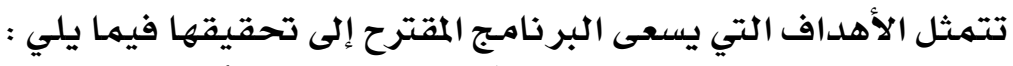

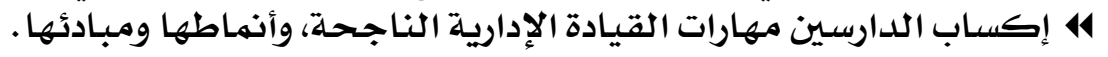

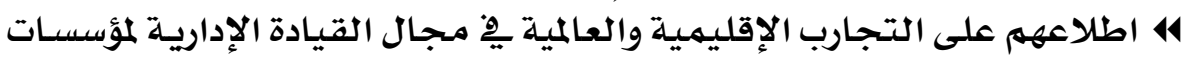

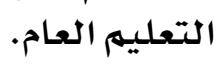

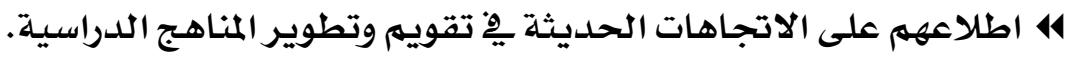

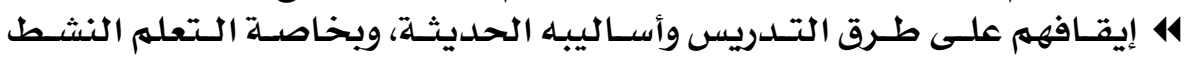

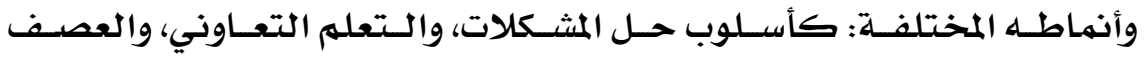

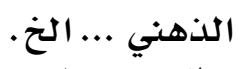

414 اطلاعهيم على طرق توظيف التقنية يِّن العمليات الإدارية.

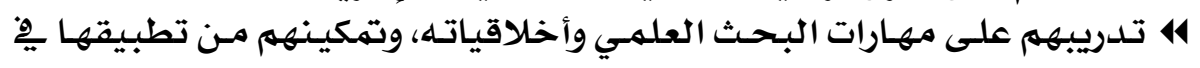

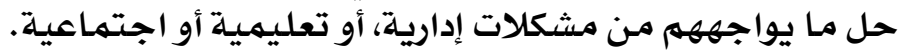

\section{$\boldsymbol{Y Y}$}




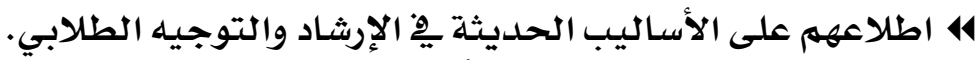

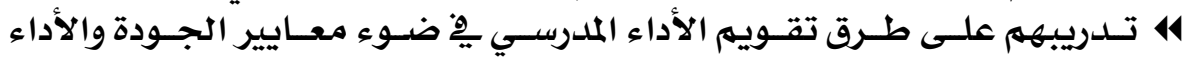
المتهيز. 4 تــريبهم على طـرق إعـداد الخطط الاسـتراتيجية للتطـوير الشـامل للعمليـة

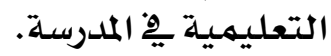

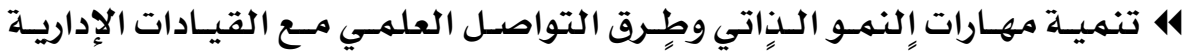

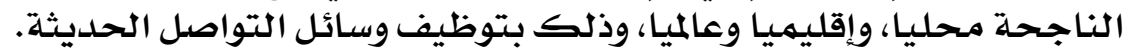

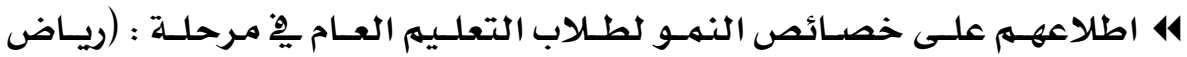

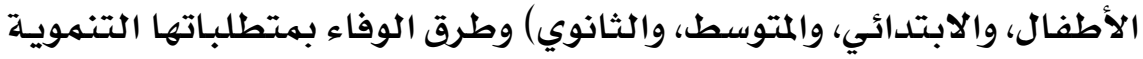

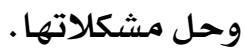

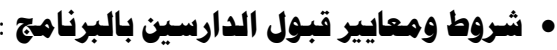

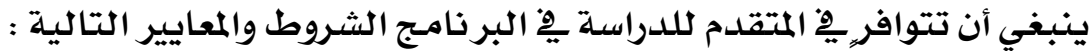

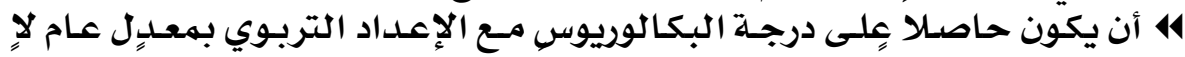

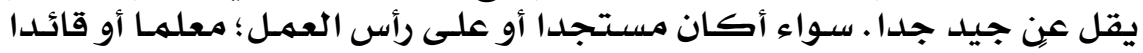
أوإداريا. 4 أن يجتاز الاختبارات التحريريـة والثفويـة التي يجريها مـركز إعـداد القيـادات الإداريـة.

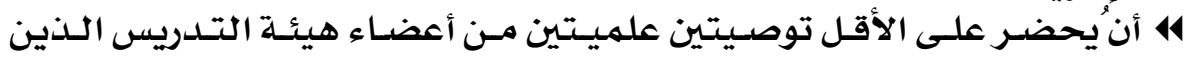
تتلمدذ عليهم. 41 أن يُحضر شهادة حسن سيرة وسِلوك.

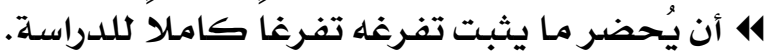

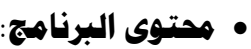

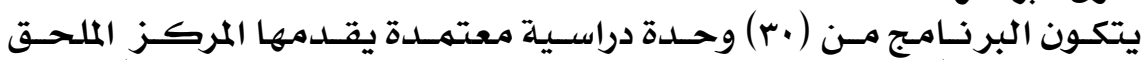

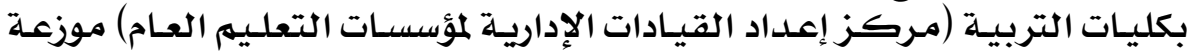

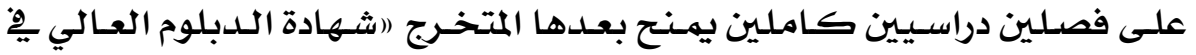

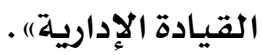

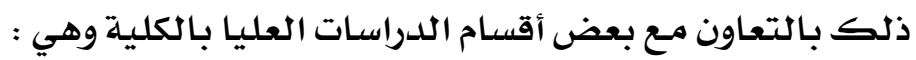

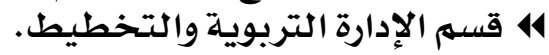

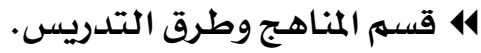

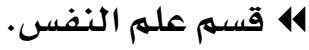
4 قسم التربية الإسـلامية. وفيما يلي تفصيل محتوى البر نامـج ونصيب كل قسم من المقررات والسـاعات

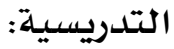

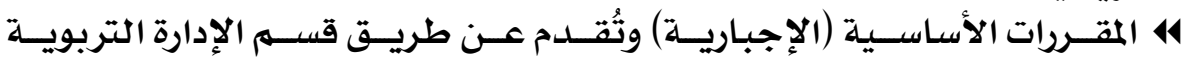
والتخطيط وهي كما يلي : الإحياريس

\section{rE}




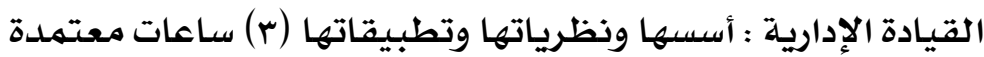

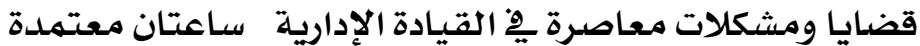

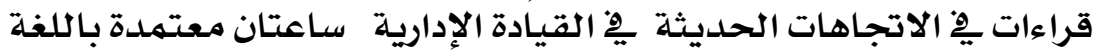

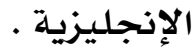

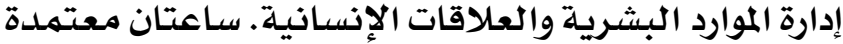

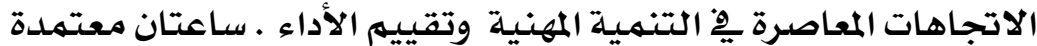

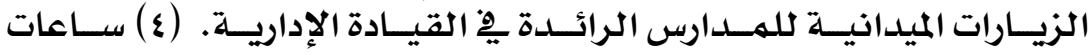

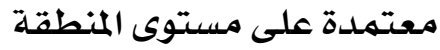

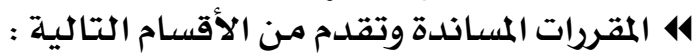

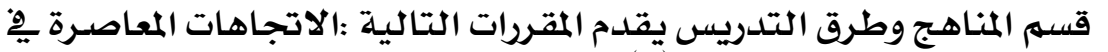

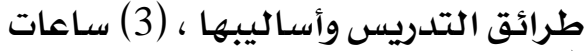

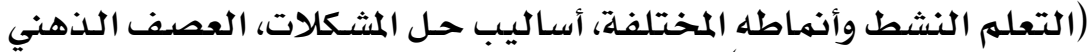

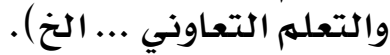

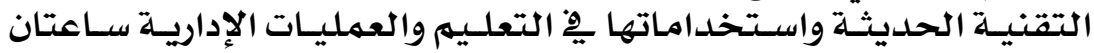

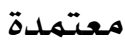

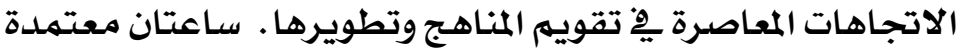

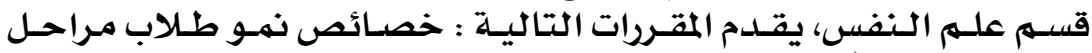

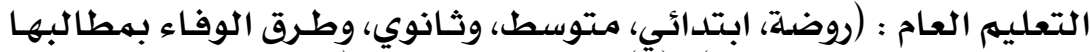

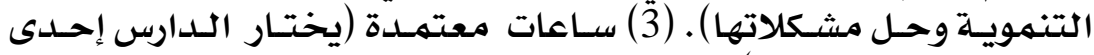

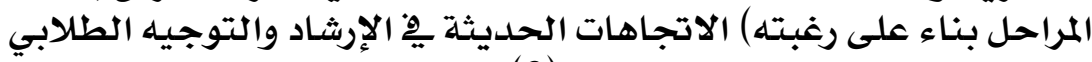

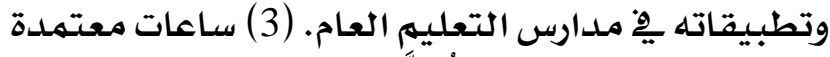

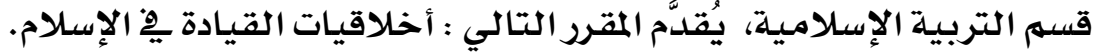

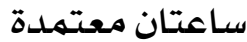

\section{• الوسائل اللازهة لتنفيذ البرناهمج:}

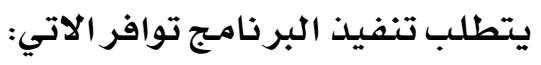

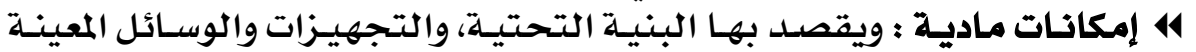

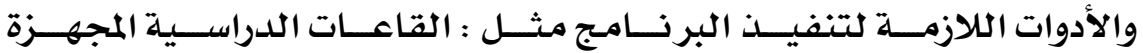

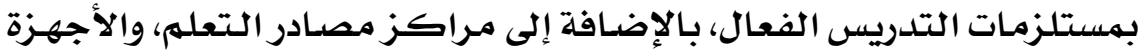

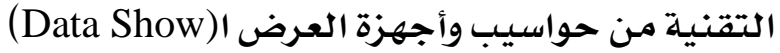

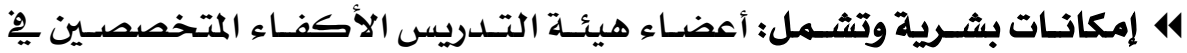

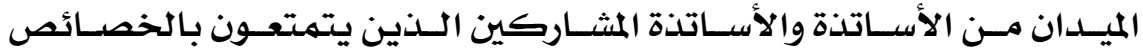

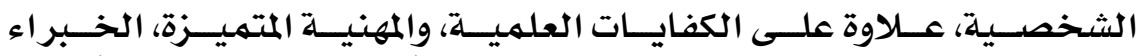

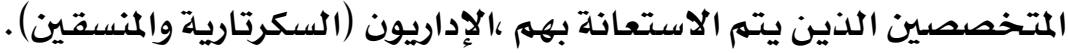

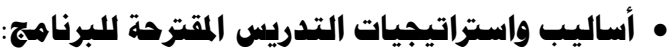

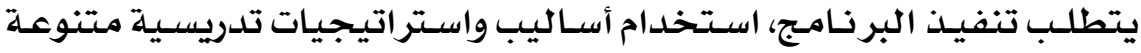

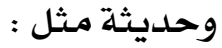

\section{ro}




$$
\text { 4 الزيارات الميدانية. }
$$

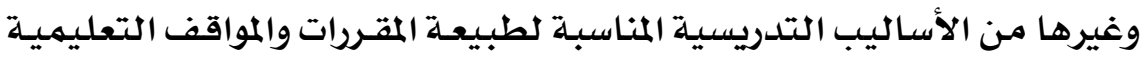

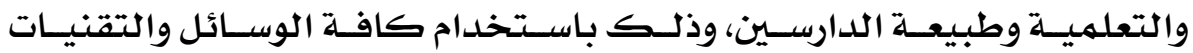

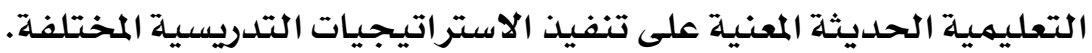

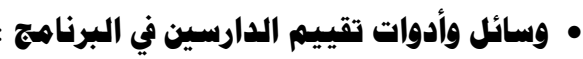

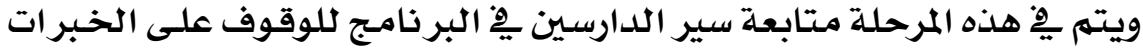

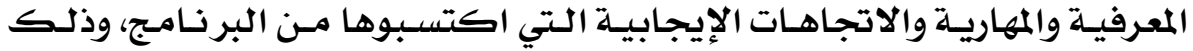

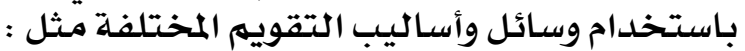
4ه الاختبارات. 414 التكليفات.

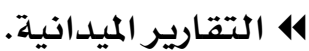

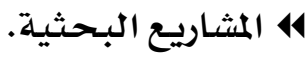
414 ملف الإنجاز.

\section{• متطلبات تنفيذ البرناهج:}

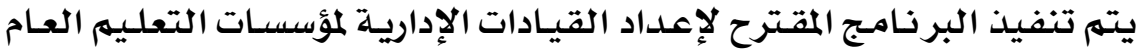

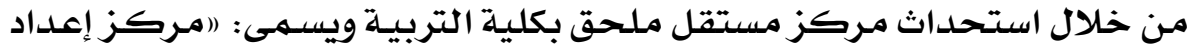

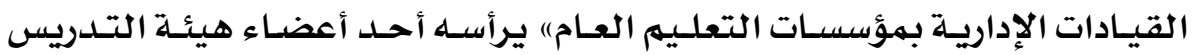

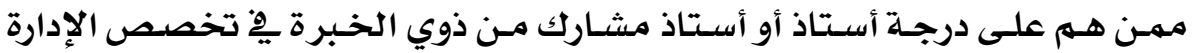

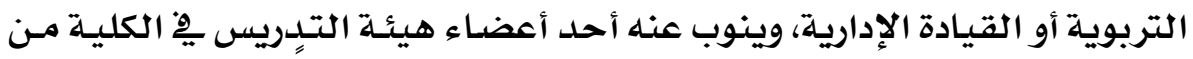

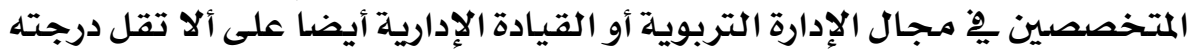
العلمية عن أستاذ مشارك.

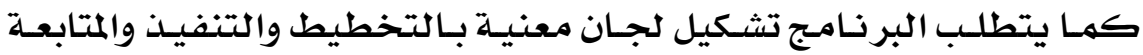

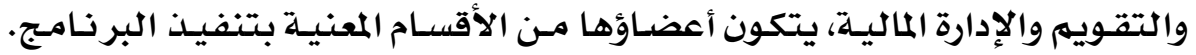

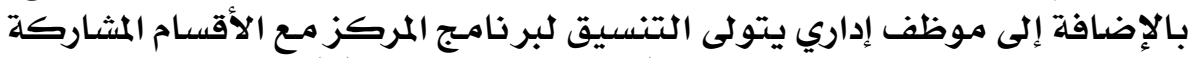

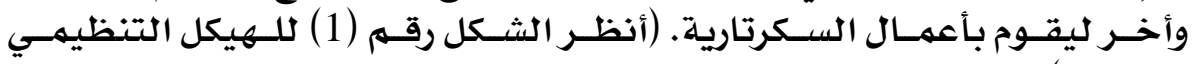

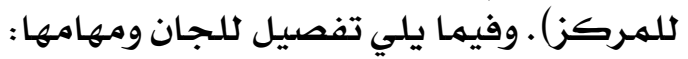

\section{ry}


• ل لجنة التخطيط وهن همامها :

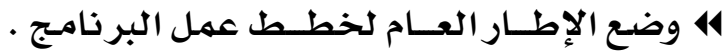

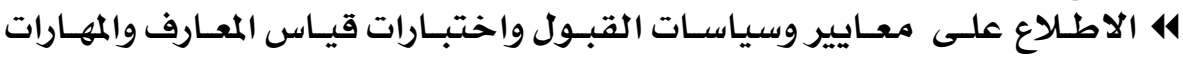

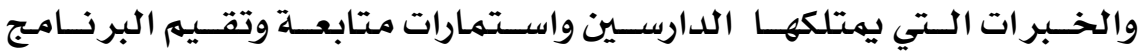

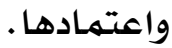

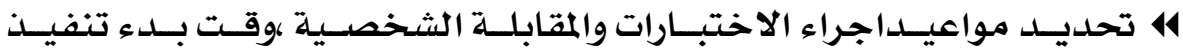
البر نامجاج. 4 اقتراح الميزانية الكلازمـة لتنفيذ البرنامـج ورسوم الالتحاق بـه.

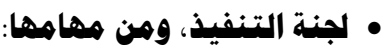

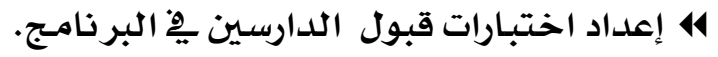

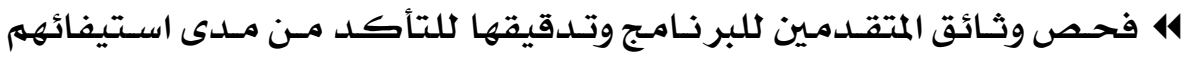

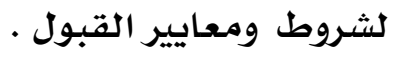

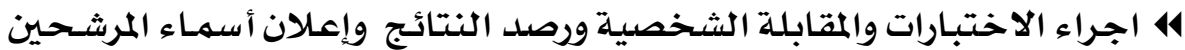

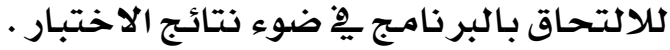
414

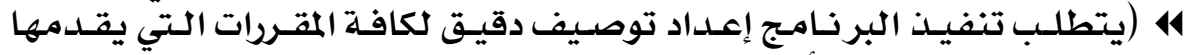

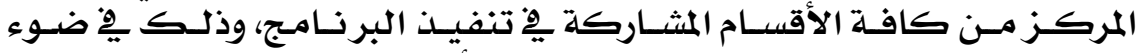

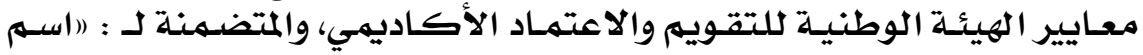

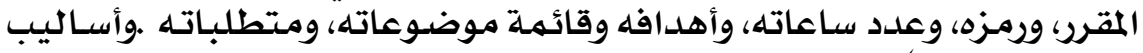

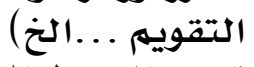
414 توزيـع الجدول الزمني للمـحاضرات والانشطة اللازمـة لتنفيذ البرنامـج .

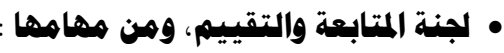

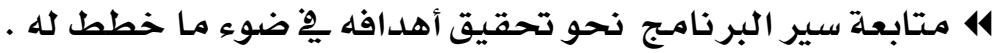

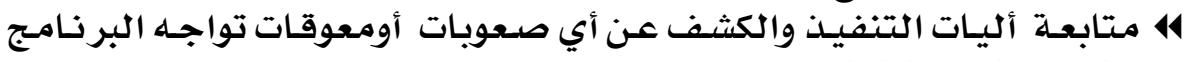

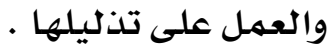
414

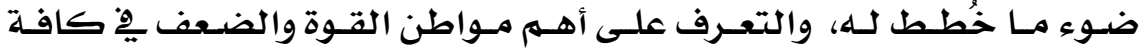

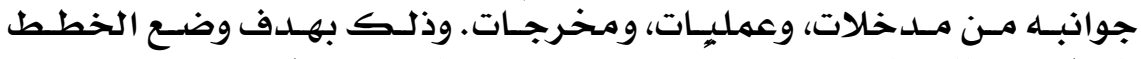

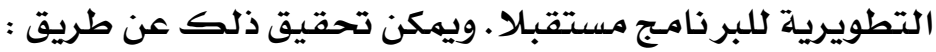

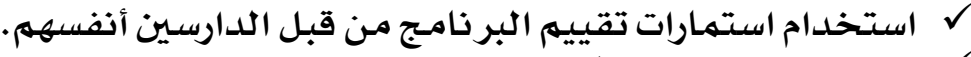

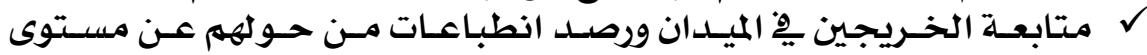
أدائهم.

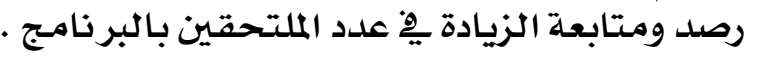

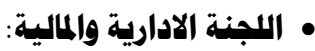

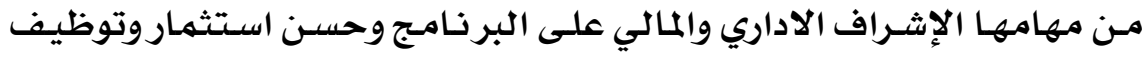
الامكانات المادية المتاحة لإثراف الادا

\section{rv}




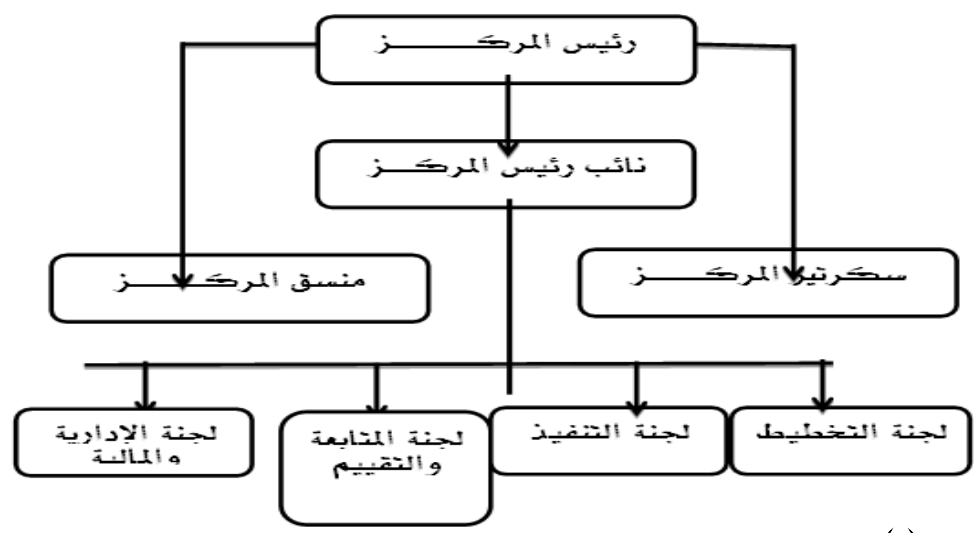

ثكل (1) يوضح الهيكل التنظيمي لمركز إعداد القيادات الإدارية لمؤسسات التعليم العام

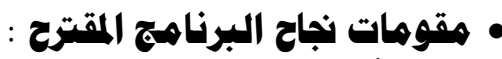

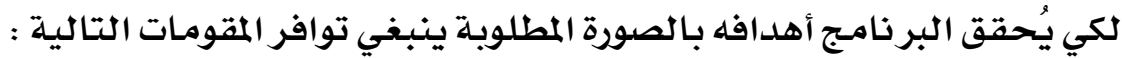

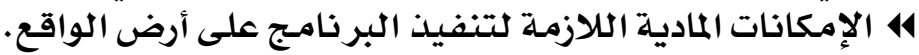

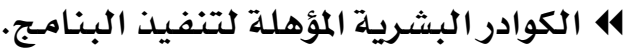

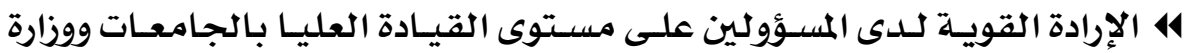

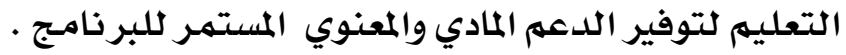

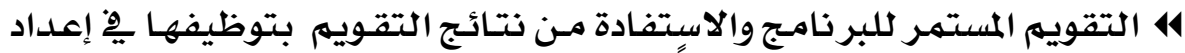

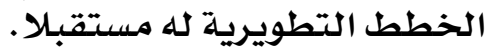

• التوصيس التوفيسات:

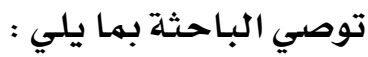

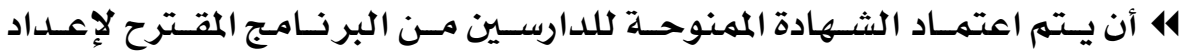

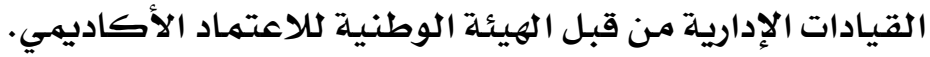

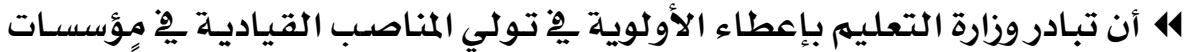

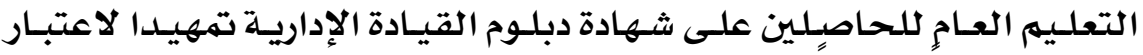

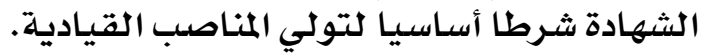

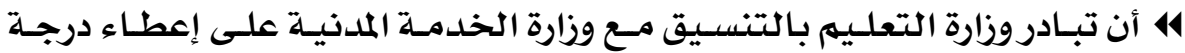

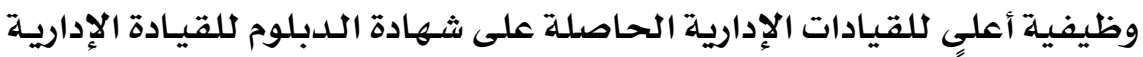

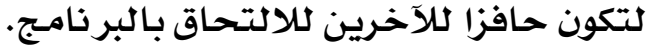

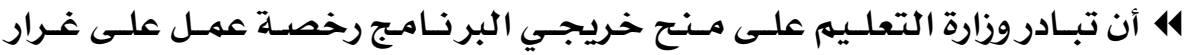
رخصة المعله.

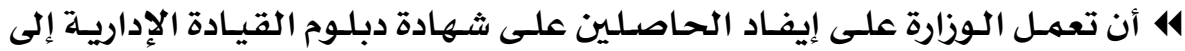

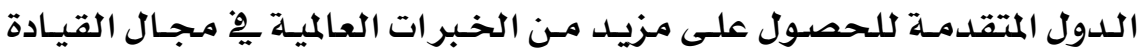

\section{rA}




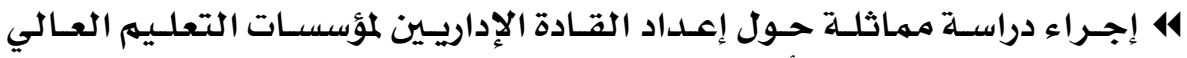

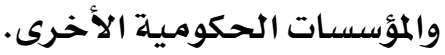

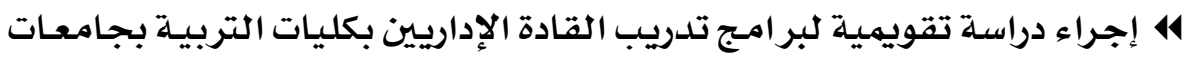

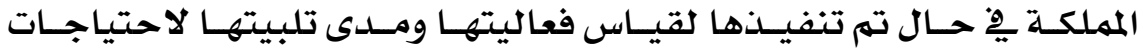

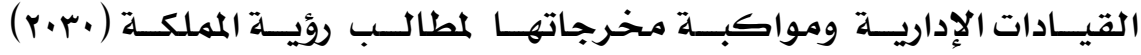

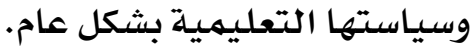

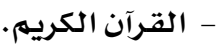

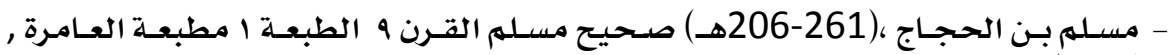

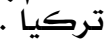

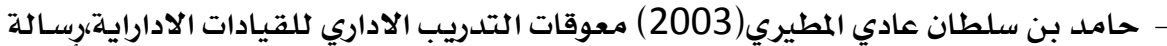

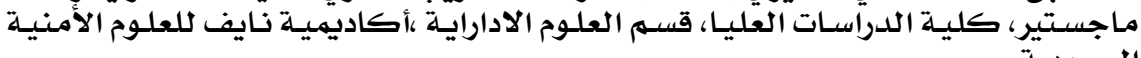
السعوديةي

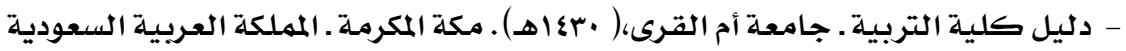

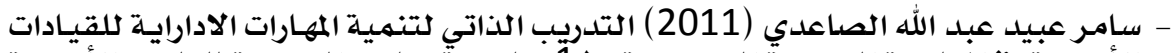

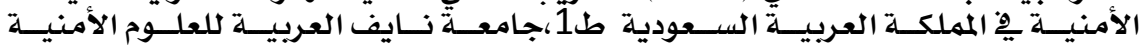

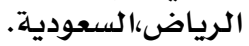

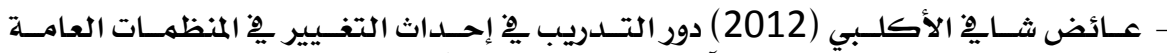

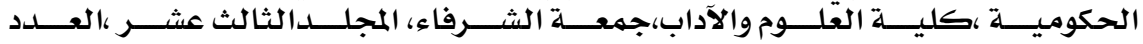

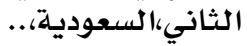

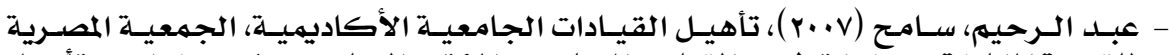

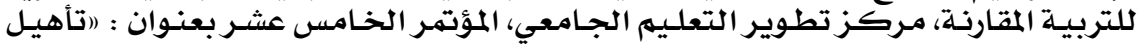

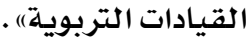

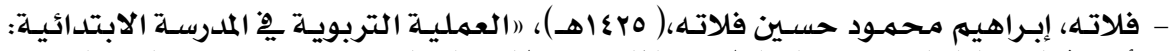

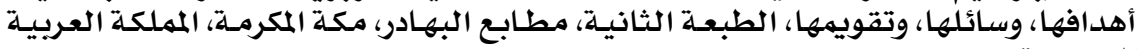

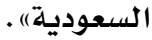

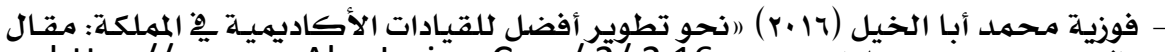

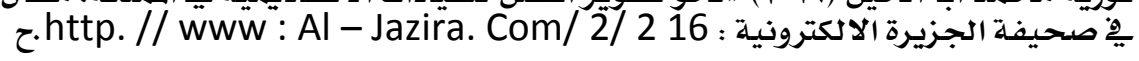

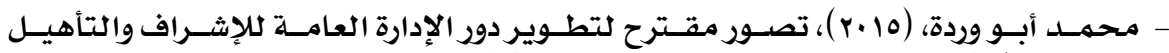

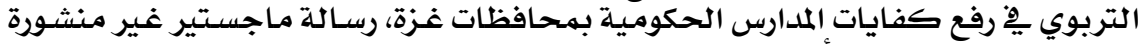

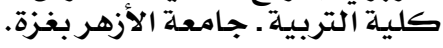

- مشروع الملك عبد الله لتطوير التعليم

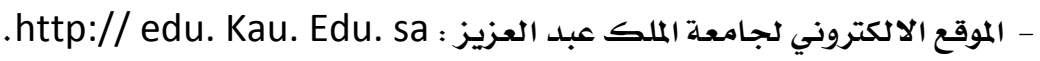

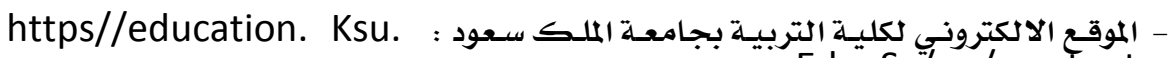
.Edu. Sa/ ar/ content

\section{rq}




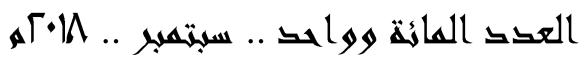

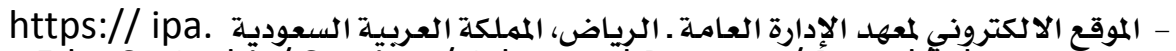
.Edu. Sa Arabic/ Services/ Advanced Program/ Paged/about. aspx

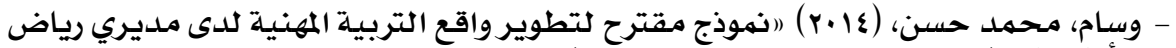

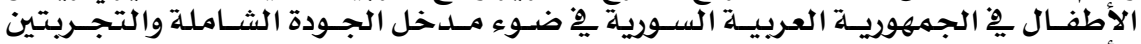
الأمريكية والبر يطانية.

\section{溇溇溇溇溇}

